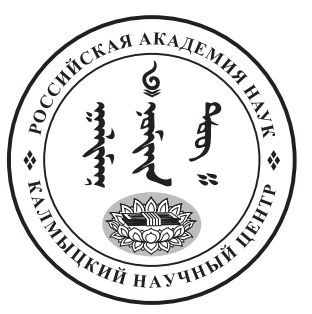

Published in the Russian Federation

Oriental Studies (Previous Name: Bulletin of the Kalmyk Institute

for Humanities of the Russian Academy of Sciences)

Has been issued as a journal since 2008

ISSN: 2619-0990; E-ISSN: 2619-1008

Vol. 14, Is. 6, pp. 1324-1352, 2021

Journal homepage: https://kigiran.elpub.ru

УДК / UDC 811.512.1

DOI: $10.22162 / 2619-0990-2021-58-6-1324-1352$

\title{
Аддитивная частица в тюркских языках Поволжья
}

\author{
Алина Алексеевна Русских 1 Софья Алексеевна Оскольская ${ }^{2}$ \\ ${ }^{1}$ Национальный исследовательский университет «Высшая школа экономики» (д. 21/4, стр. 5, \\ ул. Ст. Басманная, Москва 109028, Российская Федерация) \\ стажёр-исследователь \\ iD 0000-0002-2690-8733. E-mail: allruss@list.ru
}

${ }^{2}$ Институт лингвистических исследований РАН (д. 9, Тучков пер., Санкт-Петербург 199053, Российская Федерация)

кандидат филологических наук, старший научный сотрудник

iD 0000-0001-8658-2133. E-mail: sonypolik@mail.ru

(C) КалмНЦ РАН, 2021

(C) Русских А. А., Оскольских С. А., 2021

Аннотация. Введение. В статье рассматриваются функции аддитивной частицы $=D A$ в трех тюркских языках Поволжья: чувашском, татарском и башкирском. Подробное описание употребления аддитивной частицы включает в себя анализ как типологически ожидаемых функций, так и дополнительных функций, зафиксированных в собранном материале. Цель исследования - комплексное описание и сопоставление функций аддитивной частицы $=D A$ в тюркских языках Поволжья. Особое внимание уделяется функциям, не описанным ранее, а также межъязыковым различиям в употреблении этой частицы. Материаль и методы. Исследование основано на разных материалах: данные чувашского языка собраны методом элицитации (малокарачкинский говор). Данные татарского (мишарского диалекта) и башкирского языков (кубалякского говора) получены из опубликованных корпусов устных текстов. Резульmambl. В ходе исследования были зафиксированы следующие функции аддитивной частицы: аддитивность, скалярная аддитивность, формирование уступительных клауз, миративность, сочинение составляющих, универсальная квантификация, маркирование числительных со значением полного охвата, маркирование неопределенных местоимений, дистрибутивная множественность, употребление в составных числительных и глагольных конструкциях (сложных глаголах и сериальных конструкциях), маркирование контрастивного топика и союзных наречий. Корпусные данные показывают, что наиболее часто частица встречается в контекстах сочинения и, чуть реже, простой аддитивности. Далее следуют миративные контексты, употребление с универсальными кванторами и неопределенными местоимениями. Из всех рассмотренных ролей данным частицам дискурсивные функции не характерны и распространены только в башкирском. Также некоторые различия между языками наблюдаются в периферий- 
ных функциях, связанных с конъюнкцией: маркирование дистрибутивной множественности и употребление частицы внутри составных числительных зафиксированы только в чувашском и башкирском. Употребление частицы внутри сложных глаголов встретилось только в татарских и башкирских материалах. Наконец, только в башкирском зафиксировано употребление сериальных конструкций, в состав которых входит рассматриваемая частица. В остальном употребление частицы во всех трех языках очень похоже.

Ключевые слова: аддитивная частица, Волго-Камский языковой союз, тюркские языки, чувашский язык, татарский язык, башкирский язык, скалярность, аддитивность, конъюнкция Благодарность. Данное исследование поддержано грантом РФФИ 20-312-70009 «Грамматические особенности тюркских языков Поволжья».

Для цитирования: Русских А. А. Оскольская С. А. Аддитивная частица в тюркских языках Поволжья // Oriental Studies. 2021. T. 14. № 6. C. 1324-1352. DOI: 10.22162/2619-0990-2021-586-1324-1352

\title{
Additive Particle in Turkic Languages of the Volga-Kama Sprachbund
}

\author{
Alina A. Russkikh ${ }^{1}$, Sofia A. Oskolskaya ${ }^{2}$
}

${ }^{1}$ National Research University Higher School of Economics, Linguistic Convergence Laboratory (Bldg. 5, 21/4, Staraya Basmannaya St., 109028 Moscow, Russian Federation)

Research Assistant

iD 0000-0002-2690-8733. Email: allruss@list.ru

${ }^{2}$ Institute for Linguistic Studies of the RAS (9, Tuchkov St., 199053 St. Petersburg, Russian Federation) Cand. Sc. (Philology), Senior Research Associate

(iD)0000-0001-8658-2133.Email: sonypolik@mail.ru

(C) KalmSC RAS, 2021

(C) Russkikh A. A., Oskolskaya S. A., 2021

\begin{abstract}
Introduction. The paper deals with the functions of the additive clitic $=D A$ in three Turkic languages of the Volga-Kama Sprachbund: Chuvash, Tatar, and Bashkir. It aims to describe in detail the use of the clitic in the languages in question by way of analyzing typologically expected functions, as well as additional functions observed in the collected data, with special attention paid to those that have not been described before and on differences of its usage. Materials and methods. The analysis was based on a variety of source materials, including Chuvash data collected with elicitation during fieldwork (Maloye Karachkino variety) and Tatar (Mishar dialect), Bashkir (Kubalyak variety) data collected from published corpora of oral texts. Results. According to our data, the functions of the additive clitic $=D A$ may be as follows: proper additivity, scalar additivity, formation of the concessive clauses, mirativity, conjunction, universal quantification, marking of the numerals with collective meaning, marking of indefinites, distributive plurality, usage in complex numerals and verbal constructions (complex verbs and serial constructions), and marking of contrastive topic and conjunctional adverbs. The most frequent contexts for the additive clitic are those of conjunction, slightly less numerous are proper additivity contexts and then mirative contexts, with universal quantifiers and indefinite pronouns. The discursive functions are least typical of the additive clitic in the languages under study, except for the Bashkir material. Also, its use in peripheral, conjunctionrelated, functions may be specific: Chuvash and Bashkir data (but not Tatar) include the examples of the clitic marking distributive plurality and of its use in complex numerals; then, Tatar and Bashkir data (no data for Chuvash) indicates the use of the particle as a part of complex verbs; and, finally, only Bashkir material includes serial constructions, with the additive clitic as an obligatory part. In all the other functions, the use of the additive clitic appears to be similar in the three Turkic languages of the Volga-Kama Sprachbund.
\end{abstract}

Keywords: additive clitic, Volga-Kama Sprachbund, Turkic languages, Chuvash, Tatar, Bashkir, scalarity, additivity, conjunction

Acknowledgments. The reported study was funded by RFBR, project no. 20-312-70009 'Volga Turkic Languages: Aspects of Grammar'. 
For citation: Russkikh A. A., Oskolskaya S. A. Additive Particle in Turkic Languages of the VolgaKama Sprachbund. Oriental Studies. 2021; 14 (6): 1324-1352. (In Russ.) DOI: 10.22162/26190990-2021-58-6-13254-1352

\section{है}

\section{1. Введение}

Во всех тюркских языках зафиксирована частица $=D A$ [СИГТЯ 1988: 506]. В грамматиках для этой частицы описывается ряд функций, в частности эмфатическая, аддитивная, образование неопределенных местоимений, а также многие другие в зависимости от языка.

Далее мы будем называть эту частицу аддитивной по одной из центральных функций. Этот термин также используется в работах [König 1991; Forker 2016].

В статье подробно рассматривается и сопоставляется употребление аддитивной частицы в тюркских языках Поволжья: в чувашском, татарском и башкирском. Поскольку эти языки родственны и входят в один языковой союз, ожидается, что употребление аддитивной частицы во многом совпадает. Поэтому особый интерес будут представлять выявленные различия.

Исследование аддитивной частицы в чувашском было проведено в основном с помощью элицитации в ходе экспедиций в с. Малое Карачкино Республики Чувашия (2017-2019 г.). Малокарачкинский говор чувашского языка демонстрирует значительные отличия от литературного чувашского на фонологическом, морфосинтаксическом и лексическом уровнях. Примеры на чувашском языке взяты из материалов А. А. Русских [ПМ Русских], если не указано иное. Исследование аддитивной частицы в татарском и башкирском основано на корпусах устных текстов. Данные татарского языка получены на базе текстов, опубликованных в [Элементы 2017: 651-710].

Эти тексты были записаны в 19992000 гг. и представляют собой образцы чистопольского говора мишарского диалекта татарского языка. Объем этого корпуса составляет около 4000 словоупотреблений.

$$
\begin{array}{ll}
j e b \ddot{e}=d e & x \ddot{e} r=d e \\
\text { я=ADD } & \text { девочка }=\mathrm{ADD}
\end{array}
$$

1 Все примеры в статье приведены в той же записи и с тем же глоссированием, что и в корпусе источнике. Исключение составляет рас-
Источником для башкирских данных послужил Устный корпус башкирского языка (http://lingconlab.ru/spoken_bashkir/) [Устный корпус]. В этом корпусе собраны тексты, записанные в 2011-2017 гг. в дер. Рахметово и с. Баимово Абзелиловского района Республики Башкортостан. Эти тексты относятся к кубалякскому говору юго-восточной группы восточных говоров башкирского языка. Все примеры на башкирском языке взяты из этого корпуса, если не указано иное. Объем этого корпуса составляет около 25000 словоупотреблений ${ }^{1}$. Столь разные данные для чувашского, с одной стороны, и башкирского и татарского языков, с другой, вызваны доступностью соответствующих источников. Корпусные данные, в отличие от материалов, полученных методом элицитации, часто не позволяют однозначно определить функцию, которую выполняет частица. Тем не менее эти данные сопоставимы друг с другом и позволяют сделать ряд обобщений, которые представлены в этой работе.

\section{2. Общие сведения об аддитивных ча-} стицах в тюркских языках Поволжья

Рассматриваемые частицы используются постпозитивно. В источниках по тюркологии они описываются как распространённые в разных группах тюркских языков [СИГТЯ 1988: 512].

Чувашская клитика $=T A$ имеет фонетические варианты $=t a /=t e /=d a /=d e$ - c озвончением $\mathrm{t}$ после сонантов и в интервокальной позиции и сингармонизмом гласного с корнем по ряду: например, $\mathrm{atca}=\mathrm{da}[$ ребенок=add] 'ребенок' и pilëk=te [пять $=\mathrm{add}]$ 'все пять'. Помимо одиночной клитики $=T A$, в чувашском также есть парный союз $\mathrm{x}=T A \mathrm{y}=T A$ и редуплицированный союз tada 'и'.

$$
\begin{array}{ll}
l a v k a-j a & k a-r \text {-əmər } \\
\text { магазин-овЈ } & \text { идти-PST-1PL }
\end{array}
$$

сматриваемая частица: из соображений единообразия она везде записана со знаком «=» и глоссируется ADD. 
'Я с дочкой пошел в магазин'.

[ПМ Леонтьева]

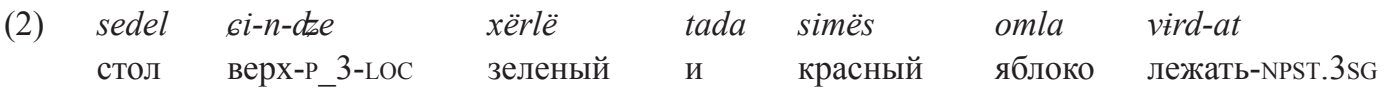

'На столе лежат красные и зеленые яблоки'.

[ПМ Леонтьева]

В татарском языке рассматриваемая частица имеет варианты $=d a /=d \ddot{a} /=t a /$ $=t \ddot{a}$. Выбор гласной также зависит от ряда гласных в предшествующем слове, а выбор согласной - от финали предшествующего слова: если слово заканчивается на гласную или звонкую согласную, используются варианты $=d a /=d \ddot{a}$, если слово заканчивается на глухую согласную - варианты $=t a /=t \ddot{a}$.

Употребление аддитивной частицы в мишарском татарском было описано в работе [Пазельская 2002].

В этой статье будут выделены дополнительные контексты употребления аддитивной частицы, не упомянутые в статье А. Г. Пазельской. Во всем корпусе [Элементы 2017: 651-710] было обнаружено 122 употребления частицы $=D A$. Таким образом, частота употреблений этой частицы в мишарском татарском составляет 0,03, или $30500 \mathrm{ipm}$.

В башкирском языке аддитивная частица имеет следующие варианты: =la / $=l \ddot{a} /=ð a /=ð \ddot{a} /=d a /=d \ddot{a} /=t a /=t \ddot{a}$ [Poppe 1964: 59]. Выбор гласной зависит от ряда гласных в предшествующем слове, а выбор согласных - от финали предшествующего слова: варианты $=l a /=l \ddot{a}$ употребляются после слова, заканчивающегося на глас-

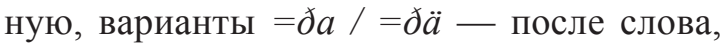
заканчивающегося на -ð, -w, -r или -j, варианты $=d a /=d \ddot{a}-$ после слова, заканчивающегося на звонкий согласный, варианты $=t a /=t \ddot{a}-$ после слова, заканчивающегося на глухой согласный. Всего в корпусе [Устный корпус] было обнаружено 727 примеров употребления аддитивной частицы. Таким образом, частота употреблений этой частицы составляет 0,029 или $29080 \mathrm{ipm}$, что сопоставимо с частотностью аддитивной частицы в мишарском татарском.

\section{3. Функции аддитивных частиц}

Отправной точкой в исследовании аддитивной частицы в тюркских языках По- волжья послужили типологические работы, посвященные похожим единицам, прежде всего [König 1991; Forker 2016].

Аддитивные частицы относятся к классу чувствительных к фокусу операторов, содержащих указание на существование как минимум одной верной альтернативы предиката для пропозиции со свободной переменной [König 1991: 33]. В качестве примеров аддитивных частиц можно привести русское тоже, английское also и немецкое auch.

В типологической статье [Forker 2016] показано, что, помимо непосредственно аддитивного значения, такие частицы часто используются в других функциях. К наиболее распространенным относятся скалярная аддитивность, контрастивный топик, образование неопределённых местоимений, уступительных клауз и союзных наречий, а также сочинение составляющих. Отношения между этими функциями могут быть представлены в виде семантической карты, где в качестве центрального значения выступает аддитивность (см. рис. 1).

В качестве периферийных и реже встречающихся у аддитивных частиц функций отмечается образование конструкций с числительными со значением полного охвата (ср. 'все три') и адвербиальных клауз со значением 'как только', 'после', 'когда' [Forker 2016: 84-85], использование в качестве комитатива и ассоциативного множественного числа [Creissels 2015], а также употребление в значении универсального квантора [Szabolcsi 2015: 160].

Ниже рассматриваются функции аддитивных частиц и их использование в малокарачкинском говоре чувашского, башкирском и мишарском татарском. Прежде всего, в разделе 4 рассматривается центральная функция - аддитивность. В разделе 5 рассматриваются функции, которые содержат скалярный компонент или диахронически связаны со скалярной аддитивностью. 


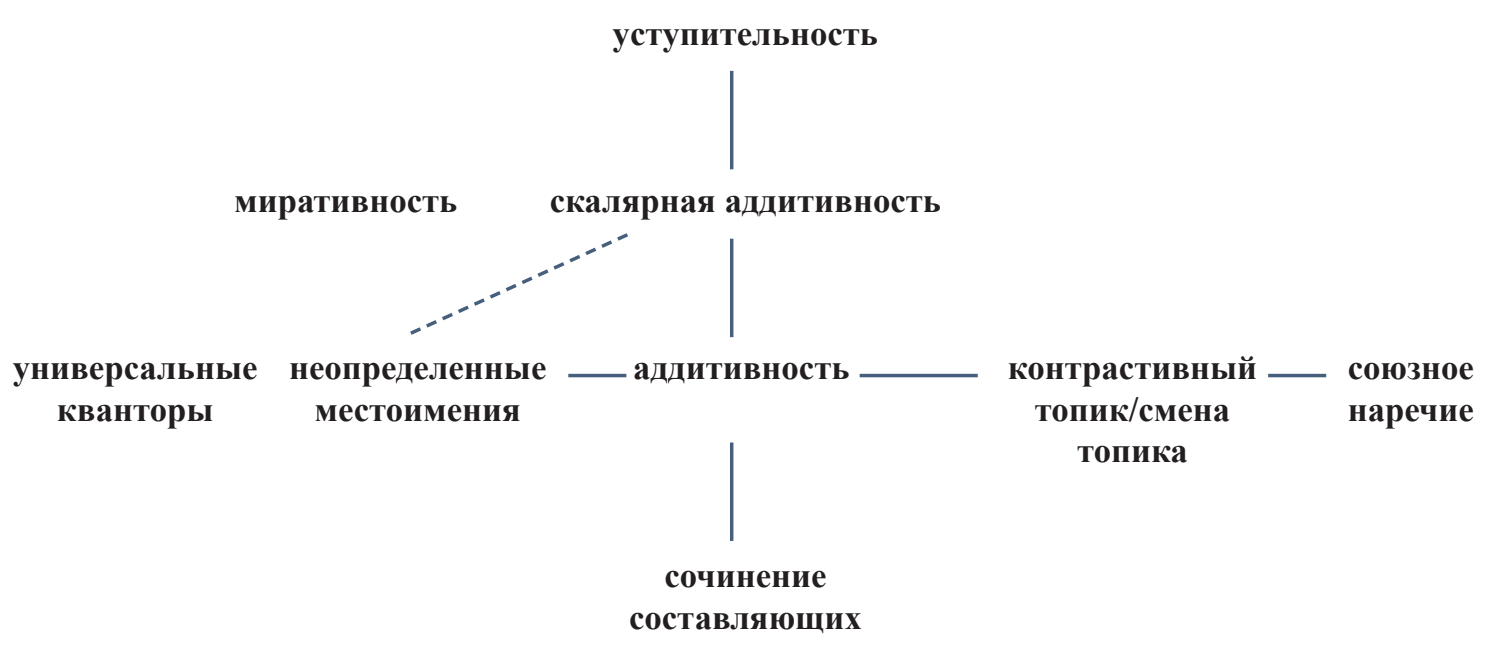

Puc. 1. Семантическая карта аддитивных маркеров ${ }^{2}$ [Forker 2016: 87]

[Fig. 1. Semantic map of additive markers]

Отдельный раздел 6 посвящен функциям, содержащим операцию конъюнкции. Раздел 7 посвящен дискурсивным функциям. Обсуждение всех функций и их сравнение в рассматриваемых языках представлено в разделе 8.

\section{4. Аддитивность}

Аддитивный оператор добавляет в семантику исходного высказывания аддитивную пресуппозицию, т. е. утверждает наличие как минимум одной верной альтернативы референта / предиката [Krifka 1999]. В [König 2017: 25] отмечается, что одной из главных особенностей фокусных частиц, в

(3) a.

$$
\begin{array}{ll}
v a s^{j} \boldsymbol{z}=d a & \text { poljk } \\
\text { Вася=ADD } & \text { полька }
\end{array}
$$

'Вася тоже танцевал польку'.

(3) b. vas'd

Вася

$$
\text { polika }=d a
$$$$
\text { полька }=\mathrm{ADD}
$$

'Вася танцевал и польку тоже'.

(3)

$$
\begin{aligned}
& \text { c. } \text { cumar-la } \text { kon-da }=d a \\
& \text { дождь-ATTR } \quad \text { день-LOC=ADD } \\
& \text { 'В дождливый день тоже красиво' }
\end{aligned}
$$

$$
\begin{array}{lll}
*_{\text {cumar }} \mathrm{la}=\mathrm{da} & \text { kon-da } & \text { xitre } \\
\text { дождь-ATTR=ADD } & \text { день-LOC } & \text { красивый }
\end{array}
$$

Некоторые носители допускают использование аддитивной клитики на конце кла-

$$
\begin{array}{lll}
\text { ?ep } & k o n-a & \text { tu-mast-ap=ta } \\
\text { я } & \text { этот-овј } & \text { делать-NEG.NPST-1sG=ADD } \\
\text { 'Я и это не буду делать' }
\end{array}
$$

[ПМ Русских].

\footnotetext{
${ }^{2}$ Перевод наш. - A. H., C. J.
} 
Аддитивная клитика $=T A$ не может относиться ко всей клаузе и использоваться в примерах типа (5) в аддитивной функции. Присоединяясь ко всей клаузе, клитика $=T A$ выполняет уже другую функцию, например
a.
petis $^{\prime}=d a$
Петя $=\mathrm{ADD}$
'Петя тоже умный'.
*‘Также Петя умный’

(5)

$$
\begin{array}{ll}
\text { b. } & \text { petis } \\
& \text { Петя } \\
& \text { 'Петя-то умный!'. } \\
\text { *‘Также Петя умный' }
\end{array}
$$

(6)

$$
\begin{array}{ll}
\text { pet's } & \text { tada } \\
\text { Петя } & \text { и } \\
\text { 'Также Петя умный' }
\end{array}
$$

В чувашском языке клитика $=T A$ в функции аддитива может присоединяться к име-

\begin{tabular}{|c|c|c|c|c|c|c|}
\hline $\begin{array}{l}\text { annarr } \\
\text { потом }\end{array}$ & $\begin{array}{l}u l \\
\text { он }\end{array}$ & $\begin{array}{l}\text { Ilwart } \\
\text { Ильварт }\end{array}$ & $\begin{array}{l}\text { jan-r-n-a } \\
\text { около-3- } \\
\text { OBL-DAT }\end{array}$ & $\begin{array}{l}\text { ker-gän } \\
\text { входить- } \\
\text { РFСТ }\end{array}$ & $\begin{array}{l}x \ddot{a ̈ m} \\
\text { и }\end{array}$ & $\begin{array}{l}\boldsymbol{a}-\boldsymbol{n} \boldsymbol{\gamma}=\boldsymbol{d} \boldsymbol{a} \\
\mathrm{OH}- \\
\mathrm{ACC}=\mathrm{ADD}\end{array}$ \\
\hline
\end{tabular}
нам - существительным, местоимениям, прилагательным, демонстративам, наречи- миративность (пример 5b). Обычно в аддитивных контекстах для добавления клаузы носители предлагают использовать tada, как в (6).
\{Моя бабушка меня очень ругала ...\} 'Потом она зашла к Ильварту и его тоже поругала'

$\partial s l a=d a$

умный $=$ ADD

[ПМ Русских]

aslo

умный

[ПМ Русских].

ям, а также к инфинитивам и причастиям. В татарском корпусе текстов было обнаружено 28 (из 122) употреблений частицы $=D A$ в аддитивной функции.

[Элементы 2017: 669].

Чаще всего частица присоединяется к именной группе. Однако также зафиксировано два примера, в которых частица относится к наречиям 'сейчас', 'сегодня'.
parallel
donja-la
ьед-ðер
параллельный
мир-LOC
MЫ-GEN
'В параллельном мире с нами живут и духи'

Из них в 49 случаях частица оформляет наречие, в 92 случаях - именную группу, в 2 случаях - предложную группу, в четы-
(9)

$\begin{array}{llll}\text { unan } & \text { huy } & \text { beð-ðe } & a l-\text {-ə } \\ \text { тот } & \text { после } & \text { мы-АСС } & \text { брать-сV }\end{array}$

'После этого нас опять повели в ресторан'

Само наречие tayə 'еще' имеет спектр рефактивных значений и тем самым близко к аддитивности: оно может выражать повтор действия или добавление. Видимо, именно этим вызвана относительно высокая частотность сочетания этого наречия с
В башкирском корпусе найдено 147 употреблений рассматриваемой частицы в аддитивной функции.

$$
\begin{array}{lll}
\text { menän } & \text { jen-där }=\text { dä } & \text { jäs̆ä-j } \\
\mathrm{c} & \text { бес-PL=ADD } & \text { жить-IPFV }
\end{array}
$$

[Устный корпус].

pex - глагольную форму. Среди наречных употреблений в 31 случае частица присоединяется к наречию tауә 'еще':

$$
\begin{array}{lll}
\text { kit-te-lär } & \text { tayə=la } & \text { restoran-ya } \\
\text { уходить-PST-PL } & \text { еще }=\mathrm{ADD} & \text { ресторан-DAT }
\end{array}
$$

[Устный корпус].

аддитивной частицей. Тем не менее употребление этой частицы с этим наречием не является обязательным.

Таким образом, во всех трех языках в функции аддитива частица =DA используется с именными группами и наречиями. Так- 
же зафиксировано употребление аддитивной частицы в этом значении с местоимениями, прилагательными, демонстративами, наречиями, инфинитивами и причастиями в чувашском языке и с предложной группой — в татарском и башкирском языках.

\section{5. Скалярность}

В настоящем разделе рассматриваются функции, которые содержат скалярный компонент или диахронически связаны со скалярной аддитивностью. Помимо собственно скалярной аддитивности, в этом разделе обсуждается формирование уступительных клауз и миративность. Если первые две функции содержат скалярный компонент, то последняя функция не содержит

$$
\begin{aligned}
& \text { a. vasə } \quad \text { pol' } k \partial=d a \\
& \text { Вася } \quad \text { полька=ADD } \\
& \text { 'Вася танцевал даже польку'. }
\end{aligned}
$$

$$
\begin{aligned}
& \text { b. } \text { cumar-la kon-da=da } \\
& \text { дождь-АTTR } \\
& \text { день-LOC=ADD }
\end{aligned}
$$

'Даже в дождливый день красиво'

Использование клитики $=T A$ в функции скалярного аддитива возможно с существительными, местоимениями, прилагательными, демонстративами, наречиями, причастиями настоящего времени и инфинитивами. его, однако предположительно связана с ним диахронически.

\section{1. Скалярная аддитивность}

Скалярная аддитивность, в отличие от простой аддитивности, не только предполагает наличие альтернатив(ы), но и упорядочивает их на шкале [König 2017: 25]. Таким образом, аддитивная частица в функции скалярного аддитива указывает на расположение референта / предиката на шкале относительно его альтернатив(ы).

В чувашском языке, как и в случае с простой аддитивностью, при кодировании скалярной аддитивности частица $=T A$ располагается за составляющей, к которой относится:

tasla-za

танцевать-CV_SIM

$$
\begin{aligned}
& * \text { cumar-la=da } \\
& \text { дождь-ATTR=ADD }
\end{aligned}
$$

kon-da
день-LOC

xitre

красивый

[ПМ Русских].

В отличие от простой аддитивности, скалярная аддитивность может также сочетаться с финитными формами глаголов, императивами и юссивами в отрицательных контекстах:

$$
\begin{aligned}
& \text { petja } \quad \text { 6ir-t6- } 2=d a \\
& \text { Петя писать-PST-3SG=ADD }
\end{aligned}
$$

[ПМ Русских].

$$
\begin{array}{ll}
\text { petjə } & \text { cir-mar-ə=de } \\
\text { Петя } & \text { писать-NEG-PST-3SG=ADD } \\
\text { 'Петя даже не написал'. } & \\
\text { *'Петя тоже не написал' } &
\end{array}
$$

[ПМ Русских].

При использовании частицы $=T A$ в функции скалярного аддитива в отрицательных контекстах с императивами и юс-

$$
\begin{array}{lll}
\text { on } & \text { bat }-n^{j} a & a n=d a \\
\text { OH.GEN } & \text { y-OBJ } & \text { PROH=ADD }
\end{array}
$$

'Даже не пиши ему!'

В корпусе текстов на мишарском татарском языке частица $=D A$ выра- сивами она может присоединяться как к прохибитивной частице an, так и к самому глаголу:

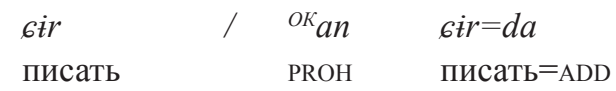

[ПМ Русских]. примерах: 


\begin{tabular}{|c|c|c|c|c|}
\hline (14) & $\begin{array}{l}\text { xätta } \\
\text { даже }\end{array}$ & $\begin{array}{l}\check{c} \ddot{a} \check{c}-e-n=d \ddot{a} \\
\text { волос-3-OBL.ACC=ADD }\end{array}$ & $\begin{array}{l}\ddot{a} n \ddot{a}-s e-n-n \ddot{a} n \\
\text { мать-3-OBL-ABL }\end{array}$ & $\begin{array}{l}\ddot{u} r-d e r-\ddot{a} . \\
\text { плести-CAUS-ST.IPFV }\end{array}$ \\
\hline
\end{tabular}

[Элементы 2017: 684].

В примере (14) скалярность выражена частицей хӓtta. Как отмечает А. Г. Пазельская [Пазельская 2002], аддитивная частица является единственным маркером скалярности в контексте отрицания, а в неотрицательных предложениях она является дополнительным маркером вме-
jen-där $=\partial \ddot{a}$
душа-PL=ADD
bel-mä-j
знать-NEG-IPFV

сте с частицей xätta. Во всех примерах частица присоединяется к именной группе, выраженной существительным или местоимением.

В башкирском корпусе обнаружено 29 примеров употребления аддитивной частицы в этой функции:

\{А о будущем людей даже шайтаны ничего не знают.\} 'Даже духи не знают'

[Устный корпус].

В отличие от татарского данная частица может выражать скалярную аддитивность и в неотрицательных предложениях без дополнительных маркеров. Тем не менее примерно половина примеров приходится на отрицательные контексты.

\section{2. Уступительные клаузы}

В ряде исследований [Forker 2016; Haspelmath 1997; и др.] отмечается, что уступительные клаузы часто содержат аддитивные частицы. Типологически частые случаи использования аддитивных частиц для формирования уступительных клауз объясняются наличием скалярного компонента в уступительных клаузах. В отличие от скалярного аддитива, сферой действия которого обычно является отдельное слово, сфера действия скалярного аддитива в уступительных клаузах распространяется на всю клаузу.

Среди уступительных клауз принято выделять два главных типа: так называемые стандартные уступительные клаузы ('standard concessive constructions') и так называемые условно-уступительные ('concessive conditionals'). Условно-уступительные клаузы делятся дополнительно на три подтипа [Haspelmath, König 1998: 563]: скалярные условно-уступительные клаузы ('even if'), универсальные условно-уступительные клаузы ('whatever'), альтернативные условно-уступительные ('whether or not'). Чаще всего аддитивная частица участвует в формировании скалярных условно-уступительных клауз [Forker 2016: 77].

\footnotetext{
3 В другой терминологии «unconditionals»
}

Стандартные уступительные конструкции - 'Хотя S1, S2' - содержат пресуппозицию, указывающую на то, что обычно пропозиции S1 и S2 рассматриваются как взаимоисключающие - в нормальном случае 'Если S1, то обычно не S2' [Forker 2016: 77].

Скалярные условно-уступительные клаузы используются для описания ситуаций, где S1 - наименее вероятный выбор на шкале. Универсальные условно-уступительные клаузы ${ }^{1}$ используются в ситуациях, где утверждается, что при любой степени S1 S1 приведет/не приведет к S2 [Forker 2016: 78].

Так как семантика S1 допускает любое расположение на шкале, в универсальных условно-уступительных клаузах в S1 обычно содержится универсальный квантор, вопросительное или неопределенное местоимение с семантикой свободного выбора [Forker 2016: 77]. Таким образом, этот подтип сближается по своей функции с употреблением аддитивной частицы при универсальных кванторах или для маркирования неопределенных местоимений (см. разделы 6.2, 6.2).

Альтернативные условно-уступительные клаузы описывают ситуацию, где, как при верном, так и неверном S1, случится S2. В таких клаузах аддитивная частица может присоединяться как к одному дизъюнкту, так и к обоим [Forker 2016: 77]. Этот подтип близок к сочинительной функции аддитивных частиц (см. раздел 6.1).

В малокарачкинском говоре чувашского языка для образования стандартных

[Zaefferer 2019]. 
уступительных клауз используется деепричастие предшествования или показатель условности tək в сочетании с аддитивной частицей. В (16а) приведен пример стандартной уступительной клаузы в чуваш-

$\begin{array}{lll}\text { (16) a. } & \text { ситәr } & \\ & \text { дождь-zan }=d a \\ & \text { мыть-CV_ANT=ADD }\end{array}$

'Хотя идет дождь, мы пойдем гулять' ском. В случае отсутствия аддитивной частицы, как в (16b), предложение остается грамматичным, однако содержит временное значение, а не уступительное. $\begin{array}{ll}\text { per } & \text { tug-a-pər } \\ \text { мы } & \text { гулять-NPST-1PL }\end{array}$

[ПМ Русских].

$\begin{array}{ll}\text { per } & \text { tug-a-pər } \\ \text { мы } & \text { гулять-NPST-1PL }\end{array}$

'Когда пойдет дождь, мы пойдем гулять'

*‘Хотя идет дождь, мы пойдем гулять’

\section{[ПМ Русских].}

Для формирования скалярных условно-уступительных клауз в малокарачкинском говоре чувашского языка используется показатель условности с аддитивной частицей. В (17a) приведен пример скалярной условно-уступительной клаузы. Без использования аддитивной частицы, как в (17b), предложение остается грамматичным, однако глагольная форма содержит только условный компонент, а не условно-уступительный. В чувашском языке для формирования универсальных условно-уступительных клауз в S1 используется неопределенное местоимение с семантикой свободного выбора, показатель времени и показатель условности с аддитивной частицей на глаголе.

$$
\begin{aligned}
& \text { a. val sana tcër-et=tëk }=t e \\
& \text { он } \quad \text { ты.оBJ } \quad \text { звать-NPST[3sG]=COND=ADD } \\
& \text { 'Даже если он позовет тебя, не приходи!' }
\end{aligned}
$$

$$
\begin{array}{ll}
\text { an } & \text { gil } \\
\text { PROH } & \text { прийти }
\end{array}
$$

\begin{tabular}{|c|c|c|c|c|c|}
\hline (18) & $\begin{array}{l}\text { mënle }=d e \\
\text { Какой }=\mathrm{ADD}\end{array}$ & $\begin{array}{l}\text { bol -in } \\
\text { быть - сONC }\end{array}$ & $\begin{array}{l}l a j ə k \\
\text { хороший }\end{array}$ & $\begin{array}{l}\text { knege } \\
\text { книга }\end{array}$ & $\begin{array}{l}6 \dot{\boldsymbol{t}}-\partial-n=d \partial k=\boldsymbol{t a} \\
\text { писать-FUT-2SG- } \\
\text { COND =ADD }\end{array}$ \\
\hline & $\begin{array}{l}*_{6 i r-\partial}-n=t ə k \\
\text { писать-FUT-2SG }= \\
\text { COND }\end{array}$ & $\begin{array}{l}\text { palə } \\
\text { знаменитый }\end{array}$ & $\begin{array}{l}\text { cin } \\
\text { человек }\end{array}$ & $\begin{array}{l}\text { pol- mes- } n \\
\text { быть - NEG.NPST } \\
-2 \mathrm{sG}\end{array}$ & \\
\hline
\end{tabular}

$\begin{array}{ll} & \text { [ПМ Русских]. } \\ & \text { gil } \\ \text { ROH } & \text { прийти }\end{array}$

[ПМ Русских].

В примере (18) также показано, что отсутствие аддитивной частицы делает пред-

Альтернативные условно-уступительные клаузы описывают ситуацию, где как при верном, так и неверном S1 случится S2. В таких клаузах аддитивная частица может присоединяться как к одному дизъюнкту, так и к обоим [Forker

$\begin{array}{lll}\text { cumar } & \text { pol-at=(te) } & \text { pol-mast=te } \\ \text { дождь } & \text { быть- } & \text { быть-NEG. } \\ & \text { NPST=ADD } & \text { NPST=ADD }\end{array}$

'Будет дождь или нет, мы все равно пойдем гулять'
[ПМ Русских].

2016: 77]. В чувашском языке возможны два варианта маркирования альтернативных условноуступительных клауз: они формируются присоединением аддитивной частицы к обоим дизьюнктам или только к последнему (см. (19)):

$\begin{array}{llll}\text { per } & \text { gulat' } & \text { tu-ma } & k a j-a-p \partial r \\ \text { мы } & \text { гулять } & \text { делать- } & \text { прийти-NPST- } \\ & & \text { INF } & 1 \text { PL }\end{array}$

[ПМ Русских]. 
В мишарском диалекте татарского языка уступительной конструкции. В этой функаддитивная частица также выступает обя- ции она присоединяется к условной форме зательным элементом при формировании глагола:

\begin{tabular}{|c|c|c|c|c|c|c|c|}
\hline (20) & $\begin{array}{l}\check{c} r r s \gamma \\
\text { елка }\end{array}$ & $\begin{array}{l}b u l-s a=d a, \\
\text { быть-COND=ADD }\end{array}$ & $\begin{array}{l}u l \\
\text { этот }\end{array}$ & $\begin{array}{l}\text { barrber } \\
\text { все.равно }\end{array}$ & $\begin{array}{l}z u r \\
\text { большой }\end{array}$ & $\begin{array}{l}\text { kerpe, } \\
\text { еж }\end{array}$ & $\begin{array}{l}d i-g \ddot{a} n . \\
\text { говорить-РFСТ }\end{array}$ \\
\hline
\end{tabular}

[Элементы 2017: 702].

В корпусе обнаружено 8 примеров упо- ют собой стандартные уступительные контребления уступительной конструкции. струкции, один - универсальную условСреди этих восьми примеров 6 представля- но-уступительную конструкцию:

\begin{tabular}{|c|c|c|c|c|c|}
\hline \multirow[t]{4}{*}{$(21)$} & kaja & bar $-s a-m=d a$ & xezmät-ey & $x a k-\gamma-n-d a$ & xermät \\
\hline & где & идти-COND-1SG=ADD & труд-2sG & $\begin{array}{l}\text { из.за-3-OBL- } \\
\text { LOC }\end{array}$ & уважение \\
\hline & bir-ä-lär & $i-k \ddot{a n}$ & $\ddot{u ̈ z-e m-n e ~}$ & $b i k$ & xermät-l-ä-de-lär. \\
\hline & $\begin{array}{l}\text { давать-ST.IPFV- } \\
\text { PL }\end{array}$ & AUX1-PFCT & cam-1sG-ACC & очень & $\begin{array}{l}\text { уважение-VRB-ST- } \\
\text { PST-PL }\end{array}$ \\
\hline
\end{tabular}

'Где бы ни была (= куда бы ни пошла), за (твой) труд, оказывается, уважают, меня очень уважали’

[Элементы 2017: 666].

В отличие от чувашского, в данном ное местоимение. Еще один пример содерпримере используется вопросительное жит скалярную условно-уступительную (или немаркированное), а не неопределен- клаузу:

\begin{tabular}{|c|c|c|c|c|c|c|c|c|}
\hline \multirow[t]{2}{*}{ (22) } & telke & ät-kän: & “šrlaj & $b u l-s a=d a$ & anar-ga & $\begin{array}{l}k \ddot{u} r-e-n-m-\ddot{a}- \\
s \ddot{a}-m\end{array}$ & jaxšr $-r a k$ & 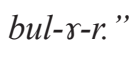 \\
\hline & лиса & $\begin{array}{l}\text { говорить- } \\
\text { РFСт }\end{array}$ & такой & $\begin{array}{l}\text { быть- } \\
\text { COND=ADD }\end{array}$ & $\begin{array}{l}\text { OH.OBL- } \\
\text { DAT }\end{array}$ & $\begin{array}{l}\text { видеть-ST- } \\
\text { PASS-NEG-ST- } \\
\text { COND-1SG }\end{array}$ & $\begin{array}{l}\text { хорошо- } \\
\text { СОмР }\end{array}$ & $\begin{array}{l}\text { быть-ST- } \\
\text { РОт }\end{array}$ \\
\hline
\end{tabular}

‘Лиса сказала: «Даже если так, лучше будет, если я ей не покажусь (= не увижусь)»’

[Элементы 2017: 700].

В башкирском языке уступительные клаузы также образуются с помощью соче-

$$
\begin{aligned}
& \text { (23) } \ddot{o j}-ð \ddot{a} r-e-n \\
& \text { дом-PL-P.3-ACC продавать-COND-PL=ADD } \\
& \text { 'И хотя их дом и продали, он там ходит' }
\end{aligned}
$$

Всего в корпусе обнаружено 28 примеров употребления уступительных предложений. Среди них представлены все четыре вида уступительных конструкций. 12 при- тания глагольной формы условного деепричастия и аддитивной частицы:

$$
\begin{array}{llll}
\text { šunda } & \text { jörö-j } & \text { tej } & u l \\
\text { тот.DAт } & \text { ходить-IPFV } & \text { сказать } & \text { тот }
\end{array}
$$

\section{[Устный корпус].}

меров представляют собой стандартные уступительные конструкции (пример 23). В 10 примерах используется скалярная условно-уступительная конструкция:

$$
\begin{array}{ll}
i \theta l a ̈-p & b u l-m a-j \\
\text { помнить-CV } & \text { быть-NEG-IPFV }
\end{array}
$$

\section{[Устный корпус]}

В 4 примерах представлены универсаль-

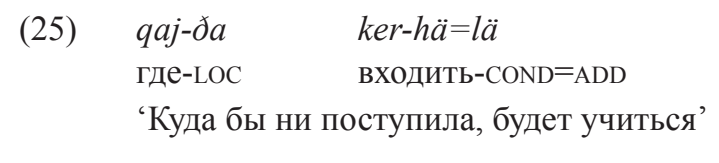

ные условно-уступительные клаузы:

$\begin{array}{ll}\text { ияә-j } & \text { inde } \\ \text { читать-IPFV } & \text { уже }\end{array}$

[Устный корпус]. 
Как и в татарском, в башкирских универсальных условно-уступительных клаузах используется вопросительное (или немаркированное) местоимение.

\begin{tabular}{|c|c|c|c|c|c|}
\hline ...Mahira & apaj & beð-gä & kil-ä & inde & asəy \\
\hline Магира & $\begin{array}{l}\text { старшая. } \\
\text { сестра }\end{array}$ & MЫ-DAT & $\begin{array}{l}\text { приходить- } \\
\text { IPFV }\end{array}$ & уже & голодать \\
\hline $\begin{array}{l}\text { asaq-ma- } \\
h a=l a\end{array}$ & $a s \partial q-h a=l a$ & kil-ä & jeygä & tip & \\
\hline $\begin{array}{l}\text { голодать- } \\
\text { NEG- } \\
\text { COND=ADD }\end{array}$ & $\begin{array}{l}\text { голодать- } \\
\text { COND=ADD }\end{array}$ & приходить-IPFV & невестка & сказать.Cv & \\
\hline
\end{tabular}
голодная ли, приходила, жена старшего брата...'

[Устный корпус].

При образовании уступительных конструкций в башкирском употребление аддитивной частицы обязательно (см.: [Грамматика 1981: 467]). При этом сама конструкция условного деепричастия в сочетании с аддитивной частицей может выражать и простые условно-временные значения без оттенка уступительности (хотя в уступительной функции эта конструкция встречается чаще).

Вероятно, в таких предложениях аддитивная частица выполняет другую функцию, например, функцию сочинения клауз (см. раздел 6.1), а условное деепричастие используется в своей основной функции.

\section{3. Миративность}

Миративное значение редко описывается среди функций аддитивных частиц. Между тем оно фиксируется для аддитивной частицы tim1 в кантонском диалекте китайского языка [Winterstein et al. 2018] и скалярного аддитива even в английском [Kim, Jahnke 2011]. Помимо миративного значения отмечается, что в английском even в конце предложения может использоваться также для уточнения говорящим предыдущего контекста (так называемые 'elaborative use') или его исправления (так называемые 'corrective use').

Согласно [Aikhenvald 2012: 473], грамматическая категория миративности может включать в себя внезапное открытие или осознание чего-либо, неожиданность, неподготовленность, контрожидание, новую информацию. Каждый из аспектов может относиться как к говорящему, так и к слушающему/аудитории или главному герою повествования. В данном разделе объединены как прототипические случаи выражения миративного значения, так и случаи, в которых уточняется или исправляется предыдущий контекст.
Наконец, в двух примерах зафиксирована альтернативная условно-уступительная конструкция:
В обеих статьях, [Kim, Jahnke 2011] и зировать миративные, уточняющие и корректирующие употребления простых и скалярных аддитивных частиц как развившиеся диахронически из значения скалярной аддитивности.

В чувашском языке частица $=T A$ может использоваться в миративном значении и для уточнения предыдущего контекста. Как можно увидеть из примеров (27)-(28), такие употребления допускаются только в тех случаях, когда аддитивная клитика занимает позицию в конце клаузы:

$$
\begin{array}{ll}
\text { atca } & \text { sumar }=d a \\
\text { ребенок } & \text { больной=ADD } \\
\text { 'Ребенок в самом деле болеет' }
\end{array}
$$

[ПМ Русских].

$$
\begin{aligned}
& a t c a=d a \quad \text { sumar } \\
& \text { ребенок=ADD больной } \\
& \text { 'Ребенок тоже болеет’. } \\
& \text { 'Даже ребенок болеет'. } \\
& \text { *'Ребенок в самом деле болеет' } \\
& \text { [ПМ Русских]. }
\end{aligned}
$$

Пример (27) возможен в двух контекстах: когда сам говорящий выражает удивление, обнаружив у ребенка признаки болезни (например, горячий лоб), или когда говорящий сообщает эту информацию слушающему, предполагая, что она будет для него неожиданной.

Уточнение обычно отражает более высокое расположение на шкале по сравнению с тем, что утверждалось ранее. Так, в примере (29) уточняется степень информированности: 'догадываться', обладать неточной информацией, заменяется на 'знать', обладать точной информацией: 


$$
\begin{array}{lll}
v a l & \text { sotla-za } & \text { peli-mes } \\
\text { он } & \text { думать-CV_SIM } & \text { знать-NEG.NPST }
\end{array}
$$

'Он не догадывается, он именно знает это'

Татарская частица $=D A$ также может использоваться в миративном контексте или для уточнения предыдущего контекста. На эти употребления указывает А. Г. Пазельская [Пазельская 2002], формулируя эти значения как «удивление: надо же!» и «частицы вот - и». Для миративного контекста «надо же!» она приводит пример, в котором частица является единственный носителем миративного значения:

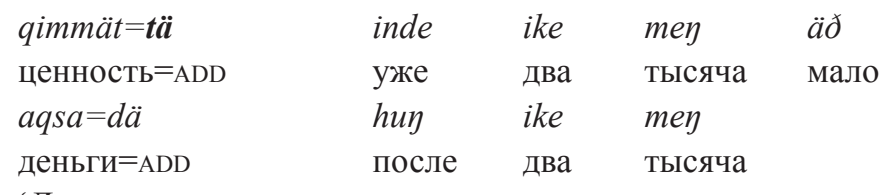

'Дорого же, две тысячи, это же ведь немалые деньги, две тысячи'

В башкирском языке аддитивная частица также употребляется в миративных контекстах:

В корпусе зафиксировано 62 употребления аддитивной частицы в миративных контекстах. В большинстве случаев также сложно однозначно утверждать, какую именно функцию выполняет частица.

\section{6. Конъюнкция}

Отдельный ряд исследований посвящен кванторным частицам, способным одновременно кодировать универсальную квантификацию (преимущественно присоединяясь к вопросительным местоимениям), аддитивность и некоторые другие функции. Семантическая связь между универсальными кванторами и аддитивностью объясняется тем, что они оба содержат операторы конъюнкции [Szabolcsi 2015: 188].

Универсальные кванторы способствуют распределению по конъюнктам, в то время как аддитивное значение предполагает конъюнкцию между предложением, содержащим аддитив, и альтернативой, которая находится в пресуппозиции. Одной из разновидностей употребления частиц в функции универсальной квантификации являются конструкции с числительными со значением полного охвата. Под этими конструкциями понимаются такие случаи, когда
[Устный корпус].

(30)

$$
\begin{array}{ll}
\text { Rišat=ta } & k i l-d e ! \\
\text { Ришат=ADD } & \text { приходить-PST } \\
\text { 'Надо же, Ришат пришел!' } & \text { [Пазельская 2002]. }
\end{array}
$$

В корпусе обнаружено 7 примеров, в которых присутствует оттенок миративности. Возможно, в большинстве из них частица также выполняет другие функции (например, маркирование неопределенных местоимений), однако выяснить это без элицитации сложно.

квантифицируемая группа выражает выбор $\mathrm{N}$ предметов из множества $\mathrm{N}$, как русское оба или французское tous les trois 'все три'.

Способность кодировать полный охват с числительными упоминается как возможное смежное значение аддитивного, однако менее частотное по сравнению с другими функциями и, в связи с этим, не помещается на семантическую карту [Forker 2016: 85].

В [Русских 2019] было показано, что объединяющим смежным значением для всех рассматриваемых в исследовании языков, кодирующих значение полного охвата с числительными с помощью аддитивных маркеров, является простая аддитивность. Это позволяет предполагать, что именно из аддитивности развивается значение полного охвата.

Союзное значение (сочинение составляющих) также является оператором конъюнкции; в некоторых случаях союзы привносят значение универсальной квантификации (см. подробнее анализ повторяющихся союзов в [Bumford 2013] как универсальных кванторов). Важной особенностью универсальных кванторов, связанных с аддитивными частицами, является дистрибутивность [Gil 1995; Szabolcsi 2015]. Дистрибутивность предполагает наличие семантически множественного компонента — индивидов 
больше двух, — который блокирует коллективные интерпретации, возможные с другими универсальными кванторами [Gil 1995: 345]. Далее использование аддитивной частицы для кодирования значения дистрибутивной множественности будет рассмотрено отдельно в разделе 6.5 .

Использование аддитивной частицы с неопределенными местоимениями объясняется, с одной стороны, их семантической близостью к универсальным кванторам - некоторые серии местоимений имеют семантику свободного выбора, ср. русское любой [Haspelmath 1997], — с другой стороны, наличием обязательного дистрибутивного компонента [Gil 1995].

Таким образом, использование аддитивной частицы для универсальной квантификации, а также употребления с неопределенными местоимениями, в союзном значении и в значении дистрибутивной множественности возможны из-за конъюнктивного компонента, который также объясняет обязательную дистрибутивную интерпретацию, появляющуюся в этих контекстах. Ниже будет рассмотрен комплекс функций аддитивных частиц, связанных с конъюнктивным компонентом: сочинение составляющих (6.1), универсальные кванторы (6.2), числительные со значением полного охвата (6.3), неопределенные местоимения (6.4), дистрибутивная множественность (6.5). Помимо этого, будут рассмотрены маргинальные употребления аддитивной частицы, также связанные, как нам кажется, с конъюнктивным компонентом: употребление аддитивной частицы внутри составных числительных (6.6), сложных глаголов и сериальных конструкций (6.7).

\section{1. Сочинение составляющих}

В экспедиционных материалах Т. Леонтьевой по малокарачкинскому чувашскому [ПМ Леонтьева] частица $=T A$ описывается как наиболее универсальное сочинительное средство: аддитивная частица может сочинять клаузы, а также глагольные, пред-

$$
\begin{array}{lllll}
\text { olja } & \text { xitre }=d e & \text { osla } & \text { xër } & \text { atca } \\
\text { Оля } & \text { красивый=ADD } & \text { умный } & \text { девушка } & \text { ребенок }
\end{array}
$$

'Оля красивая и умная девочка'.

$$
\begin{aligned}
& \text { ep oram- } a \text { tok-r-am=da man-a pit-ren sil vër }=t c e \ddot{~} \\
& \text { я улица-ОВЈ идти-PST-1SG=ADD я-овJ лицо-ABL ветер дуть=COP_PST } \\
& \text { 'Я вышел на улицу, и ветер стал дуть мне в лицо'. }
\end{aligned}
$$

[ПМ Леонтьева]

ложные, именные группы и группы прилагательного. Клитика присоединяется к первому конъюнкту:

Т. Леонтьева также отмечает, что при сочинении глаголов и клауз $=T A$ вносит семантику последовательности действий. Так, в примерах типа (33) действие в первой

$$
\begin{array}{lcc}
\text { mama }=d a & \text { рара }=d a & a t 6-i=d e \\
\text { Мама=ADD } & \text { папа }=\text { ADD } & \text { ребенок-P_3 } \\
\text { 'И мама, и папа, и ребенок пришли' } & \{\text { вся семья пришла\} }
\end{array}
$$

клаузе интерпретируется как предшествующее действию во второй клаузе, тогда как с другими сочинительными средствами такого семантического эффекта не наблюдается.

Использование $=T A$ на каждом конъюнкте привносит значение универсальной квантификации:

$$
\begin{array}{ll}
a t 6-i=d e & g i-z e \\
\text { ребенок-P_3=ADD } & \text { прийти-CV_SIM }
\end{array}
$$

[ПМ Русских].

Частица $=T A$ не может сама по себе ко-

$$
\begin{array}{ll}
a t 6 a=d a & a t 6-i=d e \\
\text { ребенок=ADD } & \text { ребенок-P_3=ADD } \\
\text { *'Все дети пришли’. } & \\
\text { 'Дети тоже пришли’ } &
\end{array}
$$

дировать универсальную квантификацию:

$$
\begin{aligned}
& g i-z e \\
& \text { прийти-CV_SIM }
\end{aligned}
$$

\section{[ПМ Русских].}

Однако при перечислении объектов возможно образование конструкции со значением полного охвата прибавлением $=T A$ к последней составляющей. Вероятно, использование ТА для кодирования полного охвата в примерах типа (36)-(37) допускается из-за того, что число индивидов в множестве известно (задано перечислением), как и в случае с числительными. 
(36)

$$
\begin{array}{lll}
a s ̧ \text { - } b a & a m ə s=t a & k a-r_{-}^{j} \text {-ə6 } \\
\text { отец.Р_3-INS } & \text { мать.P_3=ADD } & \text { прийти-PST-3PL }
\end{array}
$$

'Оба родителя ушли'

\section{[ПМ Русских].}

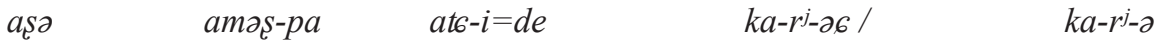

$$
\begin{aligned}
& \text { отец.P_3 мать.P_3-INS ребенок-P_3=ADD прийти-PST-3PL прийти-PST-3SG }
\end{aligned}
$$

'Мама, папа и ребенок, все трое, ушли'

[ПМ Русских].

Как и в чувашском языке, в мишарском татарском представлено два типа сочинительной конструкции с аддитивной части- цей. В первом случае аддитивная частица присоединяется только к первой составля-

\begin{tabular}{|c|c|c|c|c|}
\hline $\begin{array}{l}\text { činownik } \\
\text { чиновник }\end{array}$ & $\begin{array}{l}b \gamma \text {-lar-nr } \\
\text { этот-PL-ACC }\end{array}$ & $\begin{array}{l}\text { tan- }- \text { - } g a n=d a \\
\text { узнавать-ST- } \\
\text { PFCT }=\text { ADD }\end{array}$ & $\begin{array}{l}\text { jarløk } \\
\text { ярлык }\end{array}$ & $\begin{array}{l}j a z-\gamma-p \\
\text { писать-ST- } \\
\text { CONV }\end{array}$ \\
\hline
\end{tabular}
ющей:

'Чиновник их узнал и выписал ярлык'

Если в конструкции составляющих больше двух, то аддитивная частица присоединяется ко всем, кроме последней.

$$
\begin{array}{lll}
\text { räxmät } & \text { zawot-ta-gr } & \begin{array}{l}
\text { načalnik-lar- } \\
\text { ga=da }
\end{array} \\
\text { спасибо } & \text { завод-LOC-ATR } & \text { начальник-PL- } \\
& & \text { DAT=ADD }
\end{array}
$$

'Спасибо и заводским начальникам, и нашим председателям, и бригадирам'

$$
\begin{aligned}
& \text { üz-ebez- persidätel-lär- } \\
& \text { ney } \quad g \ddot{a}=d \ddot{a} \\
& \text { сам-1PL- председатель-PL- } \\
& \text { GEN } \quad \text { DAT }=\text { ADD } \\
& \text { brigadir-lar- } \\
& g a=d a \text {. } \\
& \text { бригадир-PL- } \\
& \mathrm{DAT}=\mathrm{ADD}
\end{aligned}
$$

[Элементы 2017: 666].
Всего в корпусе обнаружено 35 примеров на первый тип конструкции и 4 примера - на второй тип конструкции. Во всех примерах на первый тип конструкции сочинение происходит между глагольными группами, в то время как во всех четырех

\begin{tabular}{|c|c|c|c|}
\hline Šunəy & arqa-hə-nda & beð-ðеך & bašqort \\
\hline TOT.GEN & спина-Р.3-LOC & MЫ-GEN & башкир \\
\hline$r u s-s a=l a$ & bašqort-sa=la & häjbät & bel-ä-lär \\
\hline русский-ADV=ADD & башкир-ADV=ADD & хороший & знать-IPFV-PL \\
\hline
\end{tabular}
примерах на второй тип конструкции сочинение происходит между именными составляющими (существительными или местои- мениями), ср. примеры (38) и (39).

У башкирской аддитивной частицы сочинение составляющих — основная функция. На нее приходится наибольшее число употреблений в корпусе: 263. В этой функции аддитивная частица может присоединяться к каждой составляющей (пример 40) или ко всем составляющим, кроме последней (пример 41).
(40) bala-lar-ə

ребенок-PL-P.3
[Устный корпус].
$(41)$
иуa oqša-ma-nə=la mašina-nə tayə=la
TOT.DAT быть.похожим - машина-ACC еще=ADD NEG-PST $=$ ADD

'Ему это не понравилось, еще больше машину гнать начал'

[Устный корпус].

В первом случае дублирующаяся аддитивная частица участвует в сочинении именных или предложных групп, а также наречий. В корпусе представлено 22 предложения с повторяющейся частицей при сочинении. 
Во втором случае аддитивная частица участвует в сочинении клауз и присоединяется к глагольной форме или связке, т. е. к вершине клаузы. В корпусе представлено 241 предложение с такой сочинительной

$$
\begin{aligned}
& \text { (42) } \min \text { üð-em } \\
& \text { я сам-P.1SG } \\
& \text { mulla-lar } \\
& j u q=t a \\
& \text { мулла-PL }
\end{aligned}
$$

конструкцией. Отношения между клаузами могут быть как собственно сочинительными (например, при перечислении событий, следующих друг за другом), так и условно-временными:

$$
\begin{array}{lll}
\text { üð-еm } & \text { qәsqәr-yan-əm } & \text { bar } \\
\text { сам-P.1SG } & \begin{array}{l}
\text { кричать-PC.PST- } \\
\text { P.1SG }
\end{array} & \text { имеется } \\
&
\end{array}
$$

'Мне самой, когда мулл нет, самой кричать случалось'

[Устный корпус].

По всей видимости, такая взаимосвязь типа сочинительной конструкции с типом составляющих вызвана разными функциями конструкций: повторяющаяся частица маркирует универсальную квантификацию, которая в принципе в текстах чаще относится к участникам, выраженным именными группами, а не к ситуациям, выраженным глагольными группами. Обычное сочинение именных составляющих маркируется другими средствами (в башкирском языке прежде всего послелогом menän, см. [Пучкова 2017]). А единичное употребление частицы (без дублирования частицы на последнем элементе) маркирует последова-

$$
\begin{aligned}
& \begin{array}{ll}
\text { рёdёm } & a \text { tс } a=d a \\
\text { весь } & \text { ребенок=ADD }
\end{array} \\
& \text { 'Все дети пришли' } \\
& \begin{array}{ll}
\text { por } & \text { atc } a=d a \\
\text { все } & \text { ребенок=ADD }
\end{array} \\
& \text { 'Все дети пришли' }
\end{aligned}
$$

С кванторными словами pёdёт 'весь', mën-bor [что-все] 'все' и kazni 'каждый' аддитивная частица прикрепляется на вершину именной группы, как в примере выше,

$$
\begin{array}{lll}
\text { por }=d a & \text { atca-zam } & \text { gil-ze } \\
\text { все }=\text { ADD } & \text { ребенок-PL } & \text { прийти-CV_SIM } \\
\text { 'Все дети пришли' } &
\end{array}
$$

Ни с одним из кванторов $=T A$ не может использоваться для кодирования универсальной квантификации с едиными сущностями. Так, универсальный квантор pёdёm может использоваться для квантификации как единоличных сущностей, так и множе-

\section{[ПМ Русских].}

ства индивидов, однако добавление аддитивной клитики делает невозможной интерпретацию, при которой квантификация происходит над одним объектом, а не над множеством:

$$
\begin{array}{llr}
\text { pëdëm } & \text { olm- } i & \text { sip.simës } \\
\text { весь } & \text { яблоко-Р_3 } & \text { зеленый.презеленый } \\
\text { 'Всё яблоко зеленое'. / 'Все яблоки зеленые' }
\end{array}
$$




$$
\begin{aligned}
& \text { pëdёm olm-i=de } \\
& \text { весь яблоко-Р_3=ADD } \\
& \text { 'Все яблоки зеленые'. } \\
& \text { *`Всё яблоко зеленое' }
\end{aligned}
$$

В корпусе мишарского татарского зафиксированы употребления аддитивной частицы с кванторными словами хӓr 'каждый', bar 'все' и beten 'весь'. При вершинном ( субстантивированном) употребле-
'Потом мы все зашли в сад Мортазина...' sip.simes

зеленый.презеленый
[ПМ Русских].

нии квантора bar 'все' использование частицы $=D A$ является, по всей видимости, обязательным: во всех четырех примерах, зафиксированных в корпусе, есть эта частица (см. 48).

$\begin{array}{lll}\check{s} \gamma-n-n a n & s \gamma \eta & \boldsymbol{b a r}-\boldsymbol{r b} \boldsymbol{z}=\boldsymbol{d a} \\ \text { этот-ОВL-АВL } & \text { после } & \text { все-1 } \mathrm{PL}=\mathrm{ADD}\end{array}$
mrrtazin
Мортазин
bakča-s $\gamma-n-a \quad k e r-d e-k=t a ̈ .$.
сад-3-овL-
входить-PST-1 $\mathrm{PL}=\mathrm{ADD}$
DAT

[Элементы 2017: 672].

В том примере, где bar 'все' употребляется в функции модификатора ( атрибутивно) и обозначает целостность еди-

\begin{tabular}{|c|c|c|c|c|c|c|c|c|c|}
\hline (49) & ...minem & kul & $a s t-\gamma-n-d a-g \gamma$ & bar & xalsk & $\begin{array}{l}\text { ber-ber- } \\
\text { se }\end{array}$ & belän & $d u s$ & $\begin{array}{l}\text { bul-srn- } \\
\text { nar... }\end{array}$ \\
\hline & я.gen & рука & $\begin{array}{l}\text { под-3-OBL-LOC- } \\
\text { ATR }\end{array}$ & весь & народ & $\begin{array}{l}\text { один- } \\
\text { один-3 }\end{array}$ & $\mathrm{c}$ & друг & $\begin{array}{l}\text { быть- } \\
\text { JUSS-PL }\end{array}$ \\
\hline
\end{tabular}

ной сущности, а не квантификацию множества, как в (48), аддитивная частица отсутствует:

'Все (=весь народ), кто (находится) под моей властью (=рукой), пусть дружит друг с другом...’

[Элементы 2017: 698].

С кванторными словами хӓr 'каждый’ и beten 'весь' аддитивная частица используется факультативно: в корпусе она зафиксирована в одном примере со словом хӓг 'каждый'

из 6 и в двух примерах со словом beten 'весь' из 8. Во всех случаях аддитивная частица присоединяется к вершине именной группы, а не собственно к кванторному слову:

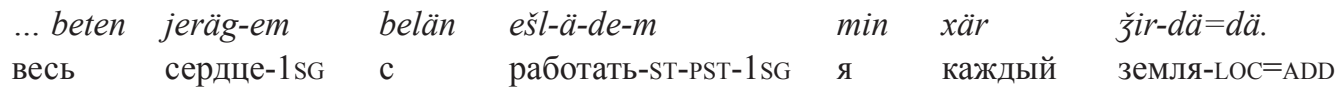
\{Я, правда, хотя сама была маленькой, очень старательно работала, чтобы среди людей не остаться в позоре, \} 'всем сердцем я везде (=в каждой земле) работала'

[Элементы 2017: 663].

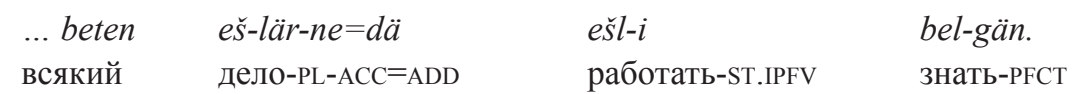

\{Уже с малых лет она росла очень умелой девочкой, 'и всякую работу умела делать'

[Элементы 2017: 702].

В примерах употребления аддитивной частицы со словами хӓr 'каждый' и beten 'весь' можно допустить, что частица появилась не только из-за контекста универсальной квантификации, но и по каким-то другим причинам, например для выражения значения миративности.

В башкирском языке для выражения универсальной квантификации используются слова här 'каждый', bötä, barə, köllö, hämmä 'весь/все' и однокоренные им (см.:
[Грамматика 1981: 158]). В корпусе зафиксированы только кванторные слова här 'каждый' и bötä 'весь/все'. Аддитивная частица употребляется преимущественно с bötä 'весь/все': 30 примеров из 39 (в конструкциях со словом här обнаружено только одно употребление аддитивной частицы из 29). Аддитивная частица употребляется только в том случае, когда кванторное слово обозначает универсальную квантификацию множества: 


\begin{tabular}{|c|c|c|c|c|c|}
\hline (52) & $\begin{array}{l}\text { häm } \\
\text { и }\end{array}$ & $\begin{array}{l}\text { šundaj } \\
\text { так }\end{array}$ & $\begin{array}{l}\ddot{o} \theta t a ̈ l-d \ddot{r} r \\
\text { стол-PL }\end{array}$ & $\begin{array}{l}\text { ine } \\
\text { быть.PST }\end{array}$ & 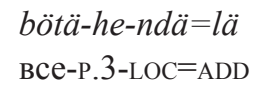 \\
\hline
\end{tabular}

[Устный корпус].

При этом кванторное слово может употребляться как самостоятельно ( в качестве

$$
\begin{aligned}
& \text { bötä } \quad \text { uүaj-ləq-tar=ða } \\
& \text { все удобный-NMLZ-PL=ADD } \\
& \text { 'Были все удобства' }
\end{aligned}
$$

вершины, см. пример 52), так и в позиции модификатора ( атрибутивно):

$\begin{array}{ll}\text { bar } & \text { ine } \\ \text { имеется } & \text { быть.PST }\end{array}$

[Устный корпус].

В первом случае аддитивная частица присоединяется собственно к кванторному слову, во втором случае - к именной груп-

пе, обозначающей множество. Также встречаются примеры, в которых аддитивная ча-

\begin{tabular}{|c|c|c|c|c|c|c|}
\hline \multirow[t]{4}{*}{ (54) } & häm & $h \ddot{r}$ & waqət-ta & иуа & böt $\ddot{a}=\mathbf{l a}$ & $n \ddot{a} m \ddot{a}-n e=\mathbf{l a ̈}$ \\
\hline & и & каждый & время-LOC & тот & весь $=$ ADD & $\begin{array}{l}\text { вещь- } \\
\mathrm{ACC}=\mathrm{ADD}\end{array}$ \\
\hline & ire-he-nsä & ešlä-r-gä & häm & röxsät & it-mä日-kä & tarəš- $a$ \\
\hline & $\begin{array}{l}\text { обратный- } \\
\text { Р.3-ADV }\end{array}$ & $\begin{array}{l}\text { работать- } \\
\text { POT-DAT }\end{array}$ & и & разрешение & $\begin{array}{l}\text { делать-NEG.POT- } \\
\text { DAT }\end{array}$ & $\begin{array}{l}\text { стараться- } \\
\text { IPFV }\end{array}$ \\
\hline
\end{tabular}
стица дублируется на обоих элементах:

'И всегда она старается делать все ей наперекор и ничего не разрешать'

[Устный корпус].

Если же кванторное слово обозначает употребляется ${ }^{1}$. Обычно в таких случацелостность единой сущности, то адди- ях кванторное слово занимает позицию тивная частица практически никогда не модификатора:
$\begin{array}{llll}\check{s} u l & \text { taš-tə } & \text { bötä } & \text { jer-ðеy } \\ \text { тот } & \text { камень-АсC } & \text { весь } & \text { земля-GEN }\end{array}$
kendeg-e tip
пупок-р.3 сказать.сV
$\begin{array}{ll}\ddot{a} j t-\ddot{a} \text {-lär } & \text { inde } \\ \text { говорить-IPFV-PL } & \text { уже }\end{array}$
'Говорят... этот камень называют пупом всей Земли'

[Устный корпус].

Во всех трех языках главным требованием аддитивной клитики $=D A$ в контекстах с универсальной квантификацией является семантическая множественность кодируемой совокупности. В связи с этим аддитивная клитика недопустима в контекстах с едиными целостными сущностями и используется только при кодировании дискретных множеств.

$$
\begin{aligned}
& \text { a. } \quad \text { ige } \quad \text { oml-i=de } \\
& \text { два яблоко-Р_3=ADD } \\
& \text { 'Оба яблока красные' }
\end{aligned}
$$

$$
\begin{array}{ll}
* \text { omla }=d a & \text { xërlë } \\
\text { яблоко }=\mathrm{ADD} & \text { красный }
\end{array}
$$

\section{ного охвата}

В малокарачкинском говоре чувашского языка значение полного охвата с числительными образуется прибавлением посессивного показателя и аддитивной клитики к вершине именной группы:

\section{[ПМ Русских].}

$$
\begin{aligned}
& \text { b. igë omla } \\
& \text { два яблоко }
\end{aligned}
$$

'Два яблока красные'

\section{[ПМ Русских].}

$$
\text { c. } \begin{aligned}
& * i g \ddot{e}=d e \\
& \text { два }=\mathrm{ADD}
\end{aligned}
$$

$$
\begin{aligned}
& \text { oml-i } \\
& \text { яблоко-Р_3 }
\end{aligned}
$$

$$
\begin{aligned}
& \text { xёrlë } \\
& \text { красный }
\end{aligned}
$$

${ }^{1}$ В корпусе зафиксирован один пример употребления аддитивной частицы в контексте целостности некоторой сущности, одна-

ко в том примере появление частицы может быть также вызвано миративным контекстом. 
Ожид. значение: 'Оба яблока красные'

[ПМ Русских].

Аддитивная клитика может также присоединяться к числительным в собирательной форме при субстантивных употреблениях:

$$
\begin{array}{ll}
i k k-\ddot{e} s=t e & x \ddot{r} l \ddot{e} \\
\text { два-COL.P_3=ADD } & \text { красный } \\
\text { 'Оба красные' } &
\end{array}
$$

$$
\text { [ПМ Русских]. }
$$

Пример (56) демонстрирует, что посессивный показатель обязателен при образовании числительных со значением полного охвата. Как показано в [Логвинова 2019], одной из основных функций посессивного показателя в малокарачкинском говоре чувашского языка является кодирование определенности. В типологическом исследовании [Русских 2019] было показано, что для ряда языков, имеющих маркер определенности, его использование обязательно для образования конструкций со значением полного охвата.

Ограничений на использование аддитивной частицы для образования конструкций со значением полного охвата с большими числительными не обнаружено. Аддитивная частица может присоединяться в этом значении как к маленьким числительным, так и к большим: $\begin{array}{lllll}\text { (58) igë } & \text { pillek/ } & \text { xërëk } & \text { at6-i=de } & k i l-t 6-\ddot{e} 6 \\ \text { два } & \text { пять } & \text { сорок } & \text { ребенок-P_3=ADD } & \text { прийти-PST-3PL }\end{array}$

'Оба / все пятеро / все сорок детей пришли'

[ПМ Русских].

Конструкции со значением полного помощью аддитивной частицы, но и с помоохвата могут быть образованы не только с щью универсальных кванторов:

$$
\begin{array}{lllll}
\text { pëdëm } & \text { igë } / & \text { xërëk } & a t 6-i=(d e) & k i l-t 6-\ddot{e} 6 \\
\text { весь } & \text { два } & \text { сорок } & \text { ребенок-P_3=ADD } & \text { прийти-PST-3PL }
\end{array}
$$

'Оба / все сорок детей пришли'

[ПМ Русских].

Числительные со значением полного охвата могут иметь как дистрибутивную, так и коллективную интерпретацию. В малокарачкинском говоре чувашского языка числительные со значением полного охвата могут использоваться с симметричными / коллективными предикатами:

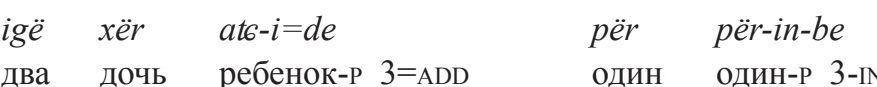

$$
\begin{aligned}
& \text { 'Две (букв. обе) девочки похожи друг на друга' }
\end{aligned}
$$

përeskel

одинаковый

[ПМ Русских].

В мишарском татарском аддитивная частица, по всей видимости, является обязательным элементом при образовании числительных со значением полного охвата.

$$
\begin{array}{lll}
\boldsymbol{i k e} \boldsymbol{e}-\boldsymbol{s}=\boldsymbol{d} \ddot{\boldsymbol{a}} & \ddot{u} l-\ddot{u}-g \ddot{a} & k e l-g \ddot{a} \\
\text { два-3= АDD } & \text { умирать-NMN- } & \text { зола-DАТ } \\
& \text { ФАТ } &
\end{array}
$$

'Обе, умерев, превратились (=превративш

Когда числительное субстантивировано, т. е. его вершина не выражена, аддитивная частица присоединяется к количественному числительному:

$\begin{array}{lll}\text { älän-e-p } & k \ddot{u k} \text {-kä } & \text { rč-a-lar } \\ \text { крутиться-ST- } & \text { небо-DAT } & \text { летать-ST. } \\ \text { CONV } & & \text { IPFV-PL }\end{array}$

[Элементы 2017: 696-697].

В корпусе обнаружен только один пример употребления числительного полного охвата. В этом примере числительное оформляется посессивным показателем 3-го л., как и в чувашском языке. В словаре татарского языка для слова 'оба' также приводится аддитивная частица [РТС 1997: 320].

В башкирском языке числительные полного охвата также маркируются с помощью аддитивной частицы. Если участники мно- 
жества выражены, то частица присоединяется к существительному, реферирующему

(62)

$\begin{array}{llllll}\text { dürt } & \text { bala-hə=la } & \text { äsä-lär-e-nä } & \text { qara-ma-j-ðar } & \text { qara-ma-j-ðar } & \text { tej } \\ \text { четыре } & \begin{array}{l}\text { ребенок- } \\ \text { P.3=ADD }\end{array} & \text { мать-PL-P.3-DAT } & \begin{array}{l}\text { смотреть-NEG- } \\ \text { смотреть-NEG- }\end{array} & \text { сказать.IPFV } \\ & & \text { IPFV-PL } & \text { IPFV-PL } & \end{array}$

'Дети не ухаживали за матерью, ой, мать, ой, дети, все четверо детей не ухаживали за матерью, не ухаживали вот'

[Устный корпус].

Если же участники множества не выражены, то числительное субстантивируется

и частица присоединяется к самому числительному:

$$
\begin{array}{ll}
i k-\ddot{a} w-h e=l \ddot{a} & \text { uqว-nə-lar } \\
\text { два-NUM.SUBST-P.3=ADD } & \text { читать-PST-PL }
\end{array}
$$

'Оба получили образование'

\section{[Устный корпус].}

Во всех случаях именная группа также оформляется показателем посессивности, который, вероятно, маркирует определенность. В корпусе обнаружено 11 примеров с числительными полного охвата, во всех случаях они оформлены аддитивной частицей.

\section{(64)}

$$
\begin{array}{lll}
k a m=d a / & * k a m & \text { bol-in } \\
\text { кто }=\text { ADD } & \text { кто } & \text { быть-CONC }
\end{array}
$$

'Кто-нибудь приходил?'
a.

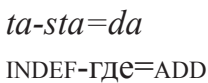

\begin{tabular}{|c|c|c|}
\hline$N i-g a m=d a$ & ${ }^{*}$ ni-gam & $\tan ^{j} \partial$ \\
\hline НИ-Кто $=\mathrm{ADD}$ & ни-кто & Таня \\
\hline$c a n-b a$ & val & $k i l^{j}-d-\ddot{e}$ \\
\hline TOT-INS & $\mathrm{OH}$ & прийти-PST-3SG \\
\hline
\end{tabular}
gravitatsi гравитация
'Где угодно есть гравитация'

$$
\begin{aligned}
& \text { b. ta-sta } \\
& \text { gravitatsi } \\
& \text { гравитация } \\
& \text { *'Где угодно есть гравитация'. } \\
& \text { 'Где-нибудь есть гравитация' }
\end{aligned}
$$

'Никто не позвал Таню, поэтому она осталась дома'

\section{4. Неопределенные местоимения}

В чувашском с помощью аддитивной частицы образуются три серии неопределенных местоимений, а именно серия на $\mathrm{X}=$ ta bolin (64), серия на ta- в контекстах с семантикой свободного выбора (65) и серия отрицательных местоимений на ni- (66).

$$
\begin{aligned}
& \text { gil-ze-j } \\
& \text { прийти-CV_SIM-Q }
\end{aligned}
$$

\section{[ПМ Русских].}

$$
\begin{aligned}
& \text { bor } \\
& \text { есть }
\end{aligned}
$$

\section{[ПМ Русских]}

bor

есть

[ПМ Русских].

prazdnik

праздник

jol-za

остаться-CV_SIM

\section{[ПМ Русских].}

Неопределенные местоимения в мишарском татарском формируются из местоименной основы, указывающей на онтологическую категорию (напр., kem ‘кто’, kaja ‘где’ и др.), и показателя серии ber в сочетании с частицей $=D A$, ällä или drr (см.: [Элементы 2017: 44]). При использовании ber употребление аддитивной частицы является обязательным.

$$
\begin{aligned}
& \text { ber-närsä }=d \ddot{a} \\
& \text { bul-m-rj, } \\
& \text { kil-sen } \\
& \text { INDEF-чTO=ADD быTь-NEG-ST.IPFV } \\
& \text { приходить-JUSS }
\end{aligned}
$$

'Ничего даже не будет (за то, что опоздала из отпуска), пусть приедет' 
Судя по зафиксированным примерам в корпусе, а также по описанию [Татарская грамматика 1993: 262], местоимения серии ber $\ldots=D A$ употребляются в отрицательных контекстах ${ }^{1}$.
Показатели серии ber ... $=D A$ обычно присоединяются к местоимениям, как в примере (67). Однако возможно также их употребление с существительными:

$$
\begin{aligned}
& \text {...ber } \quad \breve{3} i r-d \ddot{a}=d \ddot{a} \quad \text { juk bit } \\
& \text { один земля-LOC }=\text { ADD нет ведь } \\
& \{\text { Я обошел (и закончил) все поле - }\} \text { 'нигде (= ни на одной земле) (ведь) нет»', \{- робко } \\
& \text { сказал им Пашка\} }
\end{aligned}
$$

[Элементы 2017: 675-676].

В корпусе зафиксировано всего 6 примеров употребления выражений с показателями серии ber $\ldots=D A$.

Неопределенные местоимения в башкирском языке, как и в татарском, обычно

$$
\begin{aligned}
& \text { alar-ðə ber-äw }=ð \ddot{a} \\
& \text { тот-ACC один-NUM.SUBST=ADD } \\
& \text { 'Их никто не знает' }
\end{aligned}
$$

Однако, в отличие от татарского, в башкирском корпусе встречается употребление употребляются без аддитивной частицы. Исключение также составляют местоимения серии ber, которые используют-

\begin{tabular}{|c|c|c|c|c|c|c|}
\hline \multirow[t]{4}{*}{ (70) } & šunan & qajho & ber $=\partial \ddot{a}$ & bajram & $m a ̈ l-d \ddot{a r}-e$ & bul-ha \\
\hline & TOT.ABL & который & один $=\mathrm{ADD}$ & праздник & время-PL-P.3 & быть-COND \\
\hline & $s \ddot{j} j$ & es-ä-lär & elek & eske & bul-ma-nə & bit \\
\hline & чай & пить-IPFV-PL & раньше & пьянство & быть-NEG-PST & ведь \\
\hline
\end{tabular}
ся главным образом в отрицательных контекстах:

$$
\begin{aligned}
& \text { bel-mä-j } \\
& \text { знать-NEG-IPFV }
\end{aligned}
$$

[Устный корпус].

этой серии местоимений и в утвердительных предложениях:

'Потом, если был какой-нибудь праздник, — пили чай, раньше ведь пьянства не было'

Единица ber может оформлять как место(71)

$$
\begin{aligned}
& \text { ber } \quad h \ddot{u} \partial=ð \ddot{a} \quad \text { äjt-ä } \\
& \text { один слово }=\mathrm{ADD} \quad \text { говорить-IPFV } \\
& \text { 'И ни слова не смог сказать' }
\end{aligned}
$$

В корпусе зафиксировано 46 употреблений аддитивной частицы в рамках данной конструкции неопределенно-отрицательного местоимения.

\section{5. Дистрибутивная множествен- ность}

В малокарачкинском говоре чувашского языка можно выделить случаи использования аддитивной частицы для указания на дистрибутивную множественность объектов. В этой функции аддитивная частица
[Устный корпус].

именные основы, так и существительные:

$$
\begin{aligned}
& \text { al-ma-nə } \\
& \text { брать-NEG-PST }
\end{aligned}
$$

\section{[Устный корпус].}

появляется только в конструкциях с неопределенными местоимениями и универсальными кванторами, однако в контекстах, в которых не может использоваться для их образования. Так, серия неопределенных местоимений на ta- не требует аддитивной частицы в референтных неопределенных контекстах, как в (72a). Ее добавление не делает предложение неграмматичным, однако привносит значение дистрибутивной множественности, как в (72b).

$$
\text { [ПМ Русских]. }
$$

(72) b. ta-gam $=d a$ sana poloz-at

\footnotetext{
${ }^{1}$ Само слово ber ‘один’ без аддитивной ча- определенности в утвердительных контекстах. стицы может функционировать как маркер не-
} 
INDEF-KTO $=$ ADD $\quad$ ты.OBJ помогать-NPST[3sG]

'Разные люди тебе помогают'

Похожее явление возникает с универсальными кванторными словами с неисчисляемыми именами. Неисчисляемые имена являются промежуточными случаями между едиными объектами и дискретными множествами, так как обозначают некую совокупность со сложно выделяемыми отдельными атомами. C неисчисляемыми

\section{[ПМ Русских]}

объектами аддитивная клитика обычно не используется, как в (73a). Однако ее добавление возможно с привнесением дополнительного семантического компонента множественности объектов. Пример (73a), в отличие от (73b), нельзя использовать, если не предполагается, что объект находился в нескольких разных местах.

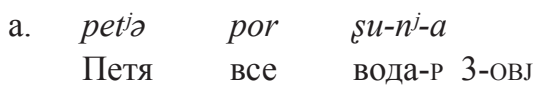$$
\ddot{e} s-s=e r-t 6-\ddot{e}
$$$$
\text { пить-CV SIM=пустить-PST-3SG }
$$

'Петя выпил вообще всю воду' \{неважно, была ли она в одном стакане или в нескольких

$$
\begin{aligned}
& \text { b. petio por } s u-n^{j}-a=d a \quad \ddot{e}_{s}-s=e r-t 6-\ddot{e} \\
& \text { Петя все вода-р_3-овJ=ADD пить-CV_sIM=пустить-PST-3SG }
\end{aligned}
$$

\{Вода была в нескольких стаканах\} 'Петя выпил всю воду'.

* \{Вода была в стакане $\}$ 'Петя выпил всю воду'

[ПМ Русских].

В корпусе мишарского татарского подобные употребления не зафиксированы. В корпусе башкирского языка один пример

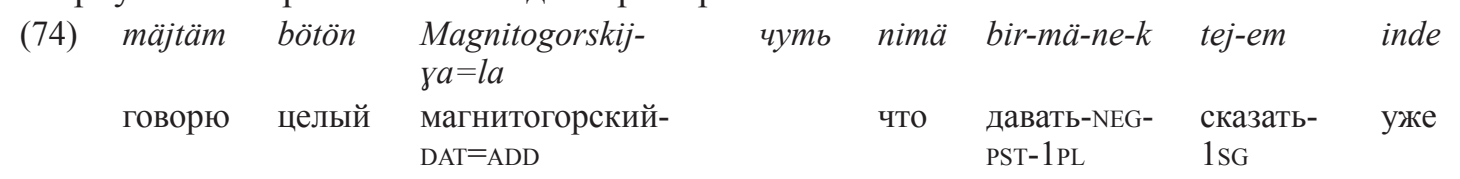

'Говорю, «мы чуть весь Магнитогорск на уши не поставили!»'

[Устный корпус].

В примере (74) 'весь Магнитогорск' можно воспринимать как дистрибутивную множественность жителей Магнитогорска.

\section{6. Составные числительные}

В башкирском языке аддитивная части-

\begin{tabular}{|c|c|c|c|}
\hline \multirow[t]{6}{*}{ (75) } & šulaj & it-ep & bəna \\
\hline & так & делать-CV & вот \\
\hline & $m e \eta=\boldsymbol{d} \ddot{\boldsymbol{a}}$ & un & dürt-ense \\
\hline & тысяча=ADD & десять & четыре-ORD \\
\hline & jal & bul-asaq & mäktäp \\
\hline & год & быть-FUT & школа \\
\hline
\end{tabular}
ца иногда употребляется внутри составных числительных:

‘Таким образом, вот скоро, в тысяча... в 2014 году будет 150 лет открытию школы'

Аддитивная частица может присоединяться к словам теу 'тысяча' или јӧठ 'сто', если за ними следует другое слово, обозна-

\begin{tabular}{|c|c|c|}
\hline tið-ðän & mey & ike \\
\hline быстрый-ABL & тысяча & два \\
\hline$j a l-d a$ & $j \ddot{\partial} \partial=\partial \ddot{a}$ & ille \\
\hline гОД-LOC & $\mathrm{cTO}=\mathrm{ADD}$ & пятьдесят \\
\hline as-əl-yan-ya & inde & \\
\hline $\begin{array}{l}\text { открывать-PASS- } \\
\text { PC.PST-DAT }\end{array}$ & уже & \\
\hline
\end{tabular}
чающее сотни, десятки или единицы.
[Устный корпус].

Такое употребление частицы не является обязательным, числительные могут употребляться и без частицы.

$\begin{array}{lll}\text { ul } & \text { waqat-ta } & \text { bal } \\ \text { тот } & \text { время-LOC } & \text { этот } \\ \text { tиуәд } & \text { jöð } & \text { tuqhan }\end{array}$




\begin{tabular}{|c|c|c|c|c|}
\hline девяносто & тысяча & девять & сто & девяносто \\
\hline biš-ense & jəl-da & ine & beð-ðеך & pasport-tar-ða \\
\hline ПяТЬ-ORD & год-LОС & быть.PST & мЫ-GEN & паспорт-PL-LOC \\
\hline millät & jað-əl-yan & waqat & inde & \\
\hline национальность & писать-PASS-PC.PST & время & уже & \\
\hline
\end{tabular}

'И... и в то время... это в девяносто... в 1995 году было: (это) было время, когда в наших паспортах была записана национальность’

Аналогичное употребление зафиксировано в текстах на малокарачкинском говоре

$$
\begin{aligned}
& \text { (77) } \mathrm{pin}=\mathrm{de} \text { vonə-məs } 6 \mathrm{l} \text {-da } \\
& \text { тысяча }=\text { ADD десять-ORD год-LOC } \\
& \text { 'В } 2010 \text { году вышла на пенсию' }
\end{aligned}
$$

В корпусе мишарского татарского такие употребления не зафиксированы.

\section{7. Глагольные конструкции}

В мишарском татарском корпусе зафик-

[Устный корпус].

чувашского языка:

$$
\begin{array}{lll}
\text { pensi } & \text { 6-in-e } & k a-r^{j} \text {-əm } \\
\text { пенсия } & \text { верх-Р_3-овЈ } & \text { подходить-PST-1SG }
\end{array}
$$

$\left(201 \_ \text {Peduchilishe_ch-46.1 }\right)^{1}$

сировано два примера, где аддитивная частица встраивается внутрь сложного глагола: она присоединяется к первой глагольной форме.

kat $-\boldsymbol{\gamma}-\boldsymbol{p}=\boldsymbol{t a}$

возвращаться-ST-CONV $=$ ADD ker-m-i.

вХодить-NEG-ST.IPFV детвора вода около-3-OBL-ABL 'Дети с речки вообще не приходят'

[Элементы 2017: 673].

Синтаксически такое употребление можно было бы трактовать как сочинение (см. раздел 6.1), если бы не семантическое единство глагольных конструкций. Вероятно, в таких случаях частица маркирует полноту действия, которая в русском языке обычно выражается словами совсем или вообще, ср. перевод примера (78).

$\begin{array}{lll}\text { (79) } & \text { tašə-j } & i k a ̈ n \\ \text { и } & \text { таскать-IPFV } & \text { быть.PC.PST } \\ \text { läkin } & \text { miskä } & \text { tul-ma-j=ða } \\ \text { но } & \text { бочка } & \text { наполняться-NEG-IPFV=ADD } \\ \text { 'И таскала, таскала, а бочка все не наполняется' }\end{array}$

Интересно, что, помимо этого, в башкирских текстах также встречаются употребления аддитивной частицы внутри так называемых сериальных конструкций. Сериальные конструкции представляют собой сочетания двух одинаковых глагольных форм для обозначения одного события. Одна из глагольных форм при этом теряет
(80) ataj $\quad \ddot{u} l-d e=l \ddot{a}$ отец умирать-PST=ADD 'Отец умер'

$\begin{array}{ll}\text { tašə-j } & i k \ddot{a} n \\ \text { таскать-IPFV } & \text { быть.PC.PST } \\ q u j-a & i k \ddot{a} n \\ \text { класть-IPFV } & \text { быть.PC.PST }\end{array}$

[Устный корпус].

В корпусе в обоих примерах употребления аддитивной частицы внутри сложного глагола глагольная вершина находится под отрицанием.

В корпусе башкирского языка обнаружено пять случаев употребления аддитивной частицы внутри сложного глагола, см. пример (79):

свое лексическое значение. По своей сути сериальные конструкции похожи на сложные глаголы, однако в сложных глаголах первый элемент выражен одним из деепричастий.

В корпусе обнаружено 12 примеров употребления сериальной конструкции, внутри которой к первому элементу присоединяется аддитивная частица: quj-ðə ставить-PST

\section{[Устный корпус]}

разработке. Ссылка состоит из номера текста, названия и номера предложения.
1 Пример взят из чувашского корпуса текстов, находящегося на данный момент в 
Аналогичные конструкции без аддитивной частицы в корпусе не обнаружены.

В малокарачкинском говоре чувашского языка подобные конструкции не зафиксированы.

Мы предполагаем, что эти конструкции появились в результате грамматикализации сочинительной глагольной конструкции, однако не можем это утверждать наверняка без дополнительного исследования.

\section{7. Дискурсивные функции}

В данном разделе описываются два типа употребления аддитивной частицы, объединенные общей функцией связи высказываний в тексте.

\section{1. Контрастивный топик}

Аддитивная частица также может использоваться в функции контрастивного топика. В таком значении аддитивная частица присоединяется к составляющей, которая контрастирует с другой составляющей, находящейся в той же сфере действия [Forker 2016: 74]. Контрастивный топик, как и простая аддитивность, указывает на наличие альтернативы.

В мишарском татарском в конструкциях с контрастивным топиком аддитивная частица обычно не употребляется:

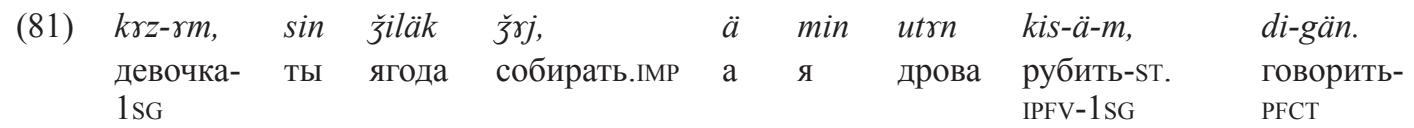

'(И) сказал: «Дочь моя, ты собирай ягоды, а я буду рубить дрова»'

[Элементы 2017: 685].

В корпусе текстов отсутствуют очевидные примеры употребления частицы $=D A$ в этой функции.

(82)

\begin{tabular}{|c|c|c|}
\hline$\ddot{a}$ & hиэ-уә & minut-ta $=l a$ \\
\hline & после-ADJ & минута-LOC $=\mathrm{AL}$ \\
\hline & unวy & ergä-he-ndä \\
\hline & EN & бок-Р.3-LOC \\
\hline
\end{tabular}

$\{$ В жизни человек ведь правильно не в ад, рядом с ним вот уговаривают'

В башкирском корпусе аддитивная частица встречается в контекстах контрастивного топика:

\begin{tabular}{|c|c|c|}
\hline una & tamuq-qa & in-der-er \\
\hline TOT.ACC & ад-DAТ & входить-CAUS-POT \\
\hline ha & 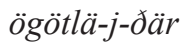 & \\
\hline & увещевать-ІР & \\
\hline
\end{tabular}

[Устный корпус].

При этом аддитивная частица может пу, как в примере (82), так и клаузу целиоформлять как топикальную именную груп- ком:

(83)

\begin{tabular}{|c|c|c|c|c|}
\hline qäjnä & $q \ddot{a} j n \ddot{a}-m$ & nimä & 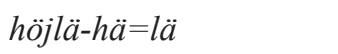 & vis \\
\hline свекровь & свекровь-P.1SG & что & говорить-COND=ADD & весь \\
\hline toyla & nej & təyla-p & tik & ultar- $a$ \\
\hline тушать & это & слушать-CV & только & сидеть-IPF \\
\hline$r-$ rajnə-m & xäðer-ge & kilen-där & təクla-ma-j=ða & $u l$ \\
\hline гоять-PLPF-1SG & сейчас-ADJ & невестка-PL & слушать-NEG-IPFV=ADD & тот \\
\hline
\end{tabular}

'Свекровь... свекровь если что говорит, всё слушала, это слушала, а теперешние снохи вовсе не слушают'

[Устный корпус].

Помимо этого, регулярно встречается частицы после союза 'если': контрастивное употребление аддитивной

\begin{tabular}{|c|c|c|c|c|c|}
\hline \multirow[t]{4}{*}{ (84) } & $\min$ & arz-nว-m & jalaq-ta-m & $\ddot{a} g \ddot{a} r=\partial \ddot{a}$ & həw-ðə \\
\hline & я & $\begin{array}{l}\text { уставать- } \\
\text { PST-1SG }\end{array}$ & $\begin{array}{l}\text { устать-PST- } \\
1 \mathrm{SG}\end{array}$ & если=ADD & вода-АСС \\
\hline & tul-tər-ma-ha-m & äsäj-em & mine & $\ddot{u} l$-ter-ä & $t i-g a ̈ n$ \\
\hline & наполняться-CAUS- & мать-P.1SG & Я.АCC & умирать-CAUS-IPFV & говорить-РС.PST \\
\hline
\end{tabular}

NEG-COND-1SG

'Я устала, замучилась, а если водой (бочку) не наполню, то мачеха меня убьет'

[Устный корпус]. 
Всего в текстах обнаружено 18 подобных примеров употребления аддитивной частицы. Однако во многих случаях сложно определить однозначно ее функцию: часто эти контексты напоминают миративные.

В малокарачкинском говоре чувашского языка аддитивная частица не используется в функции контрастивного топика.

\section{2. Союзное наречие}

В статье [Forker 2016: 81] показано, что аддитивная частица может использоваться в качестве союзного наречия со значениями 'а потом', 'кроме того', 'поэтому'. Адди- тивная частица в этой функции обычно появляется в начале предложения. В отличие от простого сочинения в функции союзного наречия аддитивная частица не устанавливает синтаксическую связь между предложениями, а помогает установить некую последовательность предложений в дискурсе.

Союзные наречия в мишарском татарском обычно употребляются без аддитивной частицы. В корпусе обнаружен только один пример употребления частицы $=D A$ в этой функции:
$\check{s} \gamma-n-n a n=d a \quad$ ul tagrn kar- $a-p$
kar-a-p
trr-gan $=d a$...
TOT-OBL-ABL $=\mathrm{ADD} \quad$ он $\quad$ снова смотреть-ST-CONV смотреть-ST-CONV стоять-PFCT=ADD 'После этого он еще пару раз посмотрел (=посмотрев, посмотрев, постоял) ...'

[Элементы 2017: 701].

В башкирском языке аддитивная частица довольно часто присоединяется к дис- курсивным словам, связывающим клаузу с предшествующим контекстом:

\begin{tabular}{|c|c|c|c|c|c|}
\hline$(86)$ & tay $\partial=\mathbf{l a}$ & bənda & ber & $m e \eta=d \ddot{a}$ & higeð \\
\hline $\mathrm{a}$ & еще $=$ ADD & этоT.DAT & один & тысяча= ADD & восемь \\
\hline jöð & ille & higeð-ense & jal-da & Räxmät & awal-ə \\
\hline сто & пятьдесят & восемь-ORD & год-LOC & Рахметово & деревня-Р.3 \\
\hline altz-nsa & kanton & üðäg-e & bul-əp & hana-l-yan & inde \\
\hline шесть-ORD & кантон & центр-Р.3 & быть-сV & считать-PASS-PC.PST & уже \\
\hline
\end{tabular}

[Устный корпус].

Эти слова могут служить как для про- 86 ), так и для выражения отношений между стого добавления новой клаузы (пример клаузами, ср. (87) с причинной связкой:

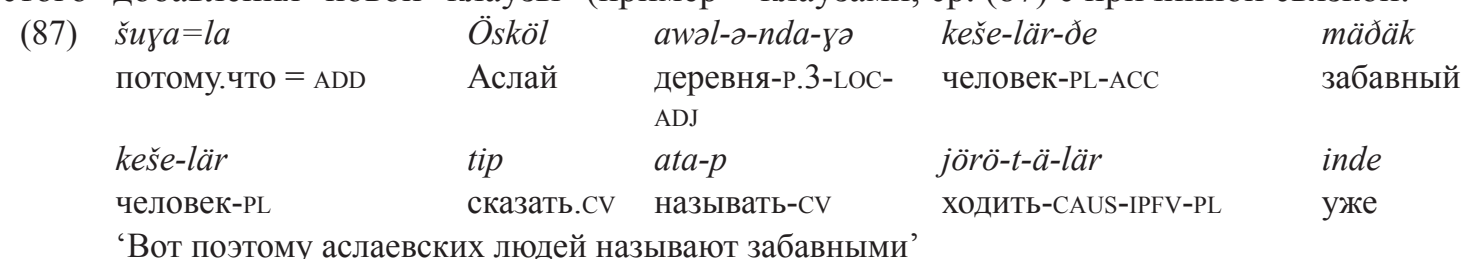

[Устный корпус].

В этой функции аддитивная частица употребляется сравнительно часто. Об этом свидетельствует 31 употребление в корпусе, а также описание некоторых союзов в грамматиках, ср. описание противительного союза šulaj=ðа в [Грамматика 1981: 354-355]. Тем не менее наличие аддитивной частицы при том или ином дискурсивном слове, по всей видимости, обязательным не является.
В малокарачкинском говоре чувашского языка использование аддитивной частицы в функции союзного наречия отсутствует.

\section{8. Обсуждение}

Полученные данные демонстрируют, что сфера употребления аддитивной частицы в тюркских языках Поволжья, как и ожидалось, во многом одинаковая. В таблице 1 обобщены сведения о разных функциях аддитивной частицы в каждом рассматриваемом языке. 
Таблица 1. Функции аддитивной частицы в чувашском, татарском, башкирском [Table 1. Functions of additive particle in Chuvash, Tatar, and Bashkir]

\begin{tabular}{|c|c|c|c|c|c|}
\hline \multicolumn{3}{|c|}{ Функция / язык } & 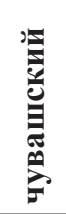 & 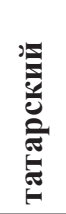 & 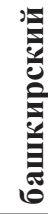 \\
\hline \multicolumn{3}{|l|}{ Аддитивность } & да & да & да \\
\hline \multirow{6}{*}{ Скалярность } & \multicolumn{2}{|c|}{ Скалярная аддитивность } & да & да & да \\
\hline & \multicolumn{2}{|l|}{ Миративность } & да & да & да \\
\hline & \multirow{4}{*}{$\begin{array}{l}\text { Уступительные } \\
\text { клаузы }\end{array}$} & стандартные & да & да & да \\
\hline & & скалярные & да & да & да \\
\hline & & универсальные & да & да & да \\
\hline & & альтернативные & да & $?$ & да \\
\hline \multirow{7}{*}{\multicolumn{2}{|c|}{ Конъюнкция }} & сочинение (одинарное) & да & да & да \\
\hline & & сочинение (дублирование) & да & да & да \\
\hline & & универсальные кванторы & да & да & да \\
\hline & & $\begin{array}{l}\text { числительные полного } \\
\text { охвата }\end{array}$ & да & да & да \\
\hline & & $\begin{array}{l}\text { неопределенные } \\
\text { местоимения }\end{array}$ & да & да & да \\
\hline & & $\begin{array}{l}\text { дистрибутивная } \\
\text { множественность }\end{array}$ & да & $?$ & да \\
\hline & & составные числительные & да & $?$ & да \\
\hline \multirow{2}{*}{\multicolumn{2}{|c|}{ Глагольные конструкции }} & сложные глаголы & нет & да & да \\
\hline & & сериальные конструкции & нет & $?$ & да \\
\hline \multirow{2}{*}{\multicolumn{2}{|c|}{ Дискурсивные функции }} & контрастивный топик & нет & нет & да \\
\hline & & союзные наречия & нет & да & да \\
\hline
\end{tabular}

* «да» означает, что в данном языке аддитивная частица используется в данной функции; «нет» — употребление в данной функции невозможно; «?» — употребление в данной функции не зафиксировано; жирным выделены «да» в тех случаях, если использование аддитивной частицы в данной конструкции является обязательным.

По данным, представленным в таблице 1 , видно, что основные функции аддитивных частиц в тюркских языках Поволжья лежат в области аддитивности, скалярности и конъюнкции. Дискурсивные же функции рассматриваемым частицам скорее не характерны и распространены только в башкирском.

В целом употребление частиц во всех трех языках похоже. Различия относятся главным образом к периферийным функциям, связанным с конъюнкцией. Так, в мало- карачкинском говоре чувашского языка и, вероятно, башкирском аддитивная частица может маркировать дистрибутивную множественность, также в этих языках аддитивная частица зафиксирована внутри составных числительных, в башкирском языке аддитивная частица может употребляться внутри сложных глаголов и сериальных конструкций. Употребление частицы внутри сложных глаголов также встретилось и в корпусе мишарского диалекта татарского языка. Примечательно, что эти функции 
аддитивной частицы в рассматриваемых тюркских языках ранее не были описаны.

Помимо этого, наблюдаются различия в том, как реализуются некоторые функции аддитивных частиц. Так, в башкирском и мишарском татарском аддитивная частица оформляет неопределенные местоимения только в отрицательных контекстах (или контекстах универсальной квантификации), в то время как в малокарачкинском говоре чувашского аддитивная частица употребляется с местоимениями и в контекстах свободного выбора.

Структура уступительных клауз в малокарачкинском говоре чувашского отличается от структуры соответствующих уступительных клауз в мишарском татарском и башкирском: в чувашском стандартные и скалярные уступительные клаузы оформляются разными глагольными формами, в то время как в башкирском и татарском для выражения этих двух значений используется одна и та же конструкция (сочетание условного деепричастия с аддитивной частицей); в универсальных условно-уступительных клаузах в малокарачкинском говоре чувашского используются неопределенные местоимения, а в мишарском татарском и башкирском вопросительные местоимения. Тем не менее аддитивная частица является обязательным элементом всех типов уступительных конструкций во всех трех языках ${ }^{1}$.

Отдельный интерес представляет миративная функции. Эта функция редко обсуждается в связи с аддитивными частицами, при этом она фиксируется во всех трех языках.

Поскольку данные по мишарскому татарскому и башкирскому языкам были взяты из корпусов, есть возможность выяснить, какие функции аддитивной частицы наиболее частотны. В таблице 2 указано количество употреблений аддитивной частицы в разных функциях.

Таблица 2. Частота употреблений аддитивной частицы в различных функциях в мишарском татарском и башкирском языках

[Table 2. Frequency use of additive particle in various functions in Mishar, Tatar, and Bashkir]

\begin{tabular}{|c|c|c|c|c|}
\hline \multicolumn{3}{|c|}{ Функция / язык } & $\begin{array}{l}\text { Татарский (ipm / } \\
\text { количество) }\end{array}$ & $\begin{array}{l}\text { Башкирский (ipm / } \\
\text { количество) }\end{array}$ \\
\hline \multicolumn{3}{|l|}{ Аддитивность } & $7000 / 28$ & $5880 / 147$ \\
\hline \multirow[t]{6}{*}{ Скалярность } & \multicolumn{2}{|c|}{ Скалярная аддитивность } & $750 / 3$ & $1160 / 29$ \\
\hline & \multicolumn{2}{|l|}{ Миративность } & $1750 / 7$ & $2480 / 62$ \\
\hline & \multirow{4}{*}{$\begin{array}{l}\text { Уступительные } \\
\text { клаузы }\end{array}$} & стандартные & $1500 / 6$ & $480 / 12$ \\
\hline & & скалярные & $250 / 1$ & $400 / 10$ \\
\hline & & универсальные & $250 / 1$ & $160 / 4$ \\
\hline & & альтернативные & 0 & $80 / 2$ \\
\hline \multirow{7}{*}{ Конъюнкция } & & сочинение (одинарное) & $8750 / 35$ & $9640 / 241$ \\
\hline & & $\begin{array}{l}\text { сочинение } \\
\text { (дублирование) }\end{array}$ & $3000 / 4(=12)$ & $2120 / 22(=53)$ \\
\hline & & $\begin{array}{l}\text { универсальные } \\
\text { кванторы }\end{array}$ & $1750 / 7$ & $1560 / 39$ \\
\hline & & $\begin{array}{l}\text { числительные полного } \\
\text { охвата }\end{array}$ & $250 / 1$ & $440 / 11$ \\
\hline & & $\begin{array}{l}\text { неопределенные } \\
\text { местоимения }\end{array}$ & $1500 / 6$ & $1840 / 46$ \\
\hline & & $\begin{array}{l}\text { дистрибутивная } \\
\text { множественность }\end{array}$ & 0 & 0 \\
\hline & & $\begin{array}{l}\text { составные } \\
\text { числительные }\end{array}$ & 0 & $640 / 16$ \\
\hline
\end{tabular}

1 Исключение составляют только альтернативные условно-уступительные клаузы в ми- шарском татарском, которые не зафиксированы в корпусе. 
Oriental Studies. 2021. Vol. 14. Is. 6

\begin{tabular}{|l|l|l|l|}
\hline \multirow{2}{*}{ Глагольные конструкции } & сложные глаголы & $500 / 2$ & $200 / 5$ \\
\hline & $\begin{array}{l}\text { сериальные } \\
\text { конструкции }\end{array}$ & 0 & $480 / 12$ \\
\hline \multirow{2}{*}{ Дискурсивные функции } & $\begin{array}{l}\text { контрастивный } \\
\text { топик }\end{array}$ & 0 & $720 / 18$ \\
\cline { 2 - 4 } & союзные наречия & $250 / 1$ & $1240 / 31$ \\
\hline ВСЕГО $^{1}$ & $30500 / 122$ & $29080 / 727$ \\
\hline
\end{tabular}

* В «Всего» указано общее количество аддитивных частиц в корпусах. Сумма употреблений по разным функциям не соответствует общему количеству, потому что, во-первых, в таблице не учтены те употребления, для которых не удалось определить функцию, и, во-вторых, в редких случаях частица может выполнять сразу две функции.

Судя по данным, представленным в таблице 2 , употребления аддитивной частицы распределяются по разным функциям в мишарском татарском и башкирском языках похожим образом. Наиболее часто аддитивная частица встречается в контекстах сочинения и, чуть реже, простой аддитивности. Далее следуют миративные контексты, употребления с универсальными кванторами и неопределенными местоимениями. Остальные употребления гораздо более редки, что связано в первую очередью с редким появлением самих типов контекстов в устных текстах. В качестве небольшого различия между языками можно отметить большую частотность башкирской аддитивной частицы в дискурсивных функциях.

\section{Список глосс}

1, 2, 3 - 1-e, 2-е, 3-е лицо; abl - аблатив; асс - аккузатив; add - аддитивность; adj — адъективизатор; adv - адвербиализатор; ant - предшествование; atr - атрибутив; attr - атрибутив; aux 1 - вспомогательный глагол 1 ; caus - каузатив; cl - классификатор; col - собирательная форма; comp - сравнительная степень; conc - уступительность; cond - кондиционалис; conv - деепричастие; cop - связка; cv - деепричастие; dat - датив; fut - будущее время; gen - генитив; imp - императив; indef - неопределенность; inf - инфинитив; ins - инструменталис; ipfv — имперфектив; juss — юссив; loc — локатив; neg — отрицание; neg.ex — эк-

\section{Полевые материалы}

ПМ Леонтьева - Леонтьева T. А. Сочинительные и комитативные конструкции. Материалы доклада, представленного в экспедиции в с. Малое Карачкино Республики Чувашия 12 июля 2019 г.

ПМ Русских - Русских $A$. А. Полевые материалы, собранные в с. Малое Карачкино Республики Чувашия в 2018-2020 гг.
Сопоставление функций аддитивной частицы в малокарачкинском говоре чувашского языка, башкирском и мишарском татарском позволяет отметить, что такие редко описываемые для аддитивной частицы функции как миративность, использование с числительными для кодирования значения полного охвата и универсальной квантификации характерны для частицы $=D A$. Вместе с тем также существует ряд периферийных функций для данной клитики, которые встречаются только для одного или двух из рассматриваемых языков. К ним можно отнести формирование глагольных конструкций, а также дискурсивные функции - контрастивный топик и союзное наречие.

зистенциальное отрицание; nmlz - номинализатор; nmn - имя действия; nom - номинатив; npst - непрошедшее время; num.subst - субстантивизатор числительного; obj - объектный падеж; obl - косвенная основа; ord — порядковое числительное; p - посессивность; pass — пассив; past - прошедшее время; рс - причастие; pfct - перфект; pfv — перфектив; pl множественное число; plpf - плюсквамперфект; pot - потенциалис; prog - прогрессив; proh - прохибитив; pst - прошедшее время; q - вопросительная частица; res - результатив; $\operatorname{sim}$ - одновременность; st - производная основа; vrb - вербализатор.

\section{Field Data}

Leontieva T. A. Coordinating and comitative constructs. Materials of Report delivered during the expedition to Maloye Karachkino (Chuvash Republic, Russian Federation) on 12 July 2019. (In Russ.)

Russkikh A. A. Field data collected in Maloye Karachkino (Chuvash Republic, Russian Federation), 2018-2020. (In Chuv.) 
Источники

Русских 2019 - Русских А. Квантификаторы со значением полного охвата в типологической перспективе. Рукопись (дипломная работа). НИУ ВШЭ СПб., 2019.

\section{Литература}

РТС 1997 - Русско-татарский словарь = Русча-татарча сүзлек: ок. 47000 слов / под ред.: Ф. А. Ганиева. 4-е изд., испр. М.: ИНСАH, 1997.720 c.

Татарская грамматика 1993 - Татарская грамматика: в 3 т. Т. 2. Морфология / РАН, АН Татарстана, Ин-т языка, лит. и истории им. Г. Ибрагимова; Казан. научн. центр; редкол.: М. З. Закиев и др. Казань: Тат. кн. издво, 1993.397 c.

Логвинова 2019 - Логвинова Н. Н. Непосессивные функции посессивного показателя третьего лица в малокарачкинском говоре чувашского языка // Acta Linguistica Petropolitana. Труды института лингвистических исследований РАН. Т. 15. Ч. 2 / гл. ред. Е. В. Головко. СПб.: ИЛИ РАН, 2019. С. $86-129$.

Устный корпус - Овсянникова М., Сай C., Аплонова Е., Сметина А., Сокур Е. Устный корпус башкирского языка дер. Рахметова и с. Баимово [электронный ресурс] // СПб.: ИЛИ РАН; М.: Международная лаборатория языковой конвергенции, НИУ ВШЭ. URL: http://lingconlab.ru/spoken_bashkir/ (дата обращения: 14.07.2021).

Пазельская 2002 - Пазельская А. Г. Дискурсивный маркер или средство синтаксической связи: частица та в чувашском и татарском языках [электронный ресурс] // Proceedings 2002. URL: http://www.dialog-21.ru/en/ digest/2002/articles/pazelskaya/ (дата обращения: 14.07.2021).

Пучкова 2017 - Пучкова А. И. Конструкции с соединительными средствами menän и häm в башкирском языке// Acta linguistica Petropolitana. Труды Института лингвистических исследований РАН. Т. ХІІІ. Ч. 1 / отв. ред. Н. Н. Казанский. СПб.: Наука, 2017. C. 255-283.

Элементы 2017 - Элементы татарского языка в типологическом освещении. Мишарский диалект / ред.: С. Г. Татевосов, А. Г. Пазельская, Д. Ш. Сулейманов. М.: Буки Веди, 2017. 764.

СИГТЯ 1988 - Сравнительно-историческая грамматика тюркских языков. Морфология / отв. ред. Э. Р. Тенишев. М.: Наука, 1988. $560 \mathrm{c}$.

Грамматика 1981 - Грамматика современного башкирского литературного языка / отв. ред. А. А. Юлдашев. М.: Наука, 1981. 495 с.

Aikhenvald 2012 - Aikhenvald A. Y. The essence of mirativity // Linguistic Typology. 2012. Vol. 16. Is. 3. Pp. 435-485.

\section{Sources}

Russkikh A. Quantifiers with a Meaning of Full Coverage: A Typological Perspective. Manuscript (B. A. thesis). St. Petersburg, 2019. (In Russ.)

Bumford 2013 - Bumford D. Universal quantification as iterated conjunction // Proceedings of the 19th Amsterdam Colloquium; Programme Committee. Aloni M., Franke M., Roelofsen F. (eds.). 2013. Pp. 67-74.

Creissels 2015 - Creissels D. Polysemy patterns involving non-scalar additive particles in Subsaharan languages: the coordinative connection. Хэндаут доклада, представленного на конференции Workshop 'Additives Across Languages'. 48th annual meeting of the Societas Linguistica Europaea (SLE 2015). Vol. 2. Leiden: Leiden University Centre for Linguistics, 2015. URL: http://www.deniscreissels.fr/public/Creissels-Additives.pdf (дата обращения 14.07.2021)

Forker 2016 - Forker D. Toward a typology for additive markers // Lingua. 180. 2016. Pp. 69100.

Gil 1995 - Gil D. Universal Quantifiers and Distributivity // Quantification in Natural Languages. Dordrecht: Springer, 1995. Pp. 321-362.

Haspelmath 1997 — Haspelmath M. Indefinite Pronouns (Oxford Studies in Typology and Linguistic Theory). Oxford: Clarendon Press, $1997.380 \mathrm{p}$.

Haspelmath, König 1998 - Haspelmath M., König E. 9 Concessive conditionals in the languages of Europe // Adverbial Constructions in the Languages of Europe. J. Van der Auwera, D. P. O Baoill (eds.). Berlin, New York: De Gruyter Mouton. 2011. Pp. 563-640.

Kim, Jahnke 2011 - Kim M.-J., Jahnke N. The Meaning of Utterance-Final Even // Journal of English Linguistics. 2011. Vol. 39. Is. 1. Pp. 36-64.

König 1991 - König E. The Meaning of Focus Particles: A Comparative Perspective. London; New York: Routledge, 1991. 218 p.

König 2017 - König E. Syntax and semantics of additive focus markers from a cross-linguistic perspective // Focus on additivity: Adverbial modifiers in Romance, Germanic and Slavic languages. A.-M. De Cesare, C. Andorno (eds.). Amsterdam: John Benjamins, 2017. Pp. 23-44.

Krifka 1999 - Krifka M. Additive particles under stress // Semantics and Linguistic Theory. Vol. 8. 1998. Pp. 111-128.

Poppe 1964 - Poppe N. Bashkir manual: descriptive grammar and texts with a BashkirEnglish glossary. The Hague: Mouton \& Co., 1964. $181 \mathrm{p}$.

Szabolcsi 2015 - Szabolcsi A. What do quantifier particles do? // Linguistics and Philosophy. 2015. Vol. 38. Is. 2. Pp. 159-204. 
Winterstein et al. 2018 - Winterstein G., Lai R., Lee D. T. H., Luk Z. P. S. From additivity to mirativity: The Cantonese sentence final particle tim1 // Glossa: a journal of general linguistics. Vol. 3. Is. 1. 2018. Pp. 1-38.

\section{References}

Aikhenvald A. Y. The essence of mirativity. Linguistic Typology. 2012. Vol. 16. No. 3. Pp. 435-485. (In Eng.)

Bumford D. Universal quantification as iterated conjunction. In: Aloni M., Franke M., Roelofsen F. (eds.) Proceedings of the 19th Amsterdam Colloquium. 2013. Pp. 67-74. (In Eng.)

Creissels D. Polysemy patterns involving non-scalar additive particles in Sub-Saharan languages: The coordinative connection. In: Additives Across Languages. 48th Annual Meeting of the Societas Linguistica Europaea (SLE 2015). Vol. 2. Leiden: Leiden University Centre for Linguistics, 2015. Available at: http://www. deniscreissels.fr/public/Creissels-Additives.pdf (accessed: July 14, 2021). (In Eng.)

Forker D. Toward a typology for additive markers. Lingua. 2016. No. 180. Pp. 69-100. (In Eng.)

Ganiev F. A. Russian-Tatar Dictionary. 4th ed., rev. Moscow: INSAN, 1997. 720 p. (In Russ. and Tat.)

Gil D. Universal quantifiers and distributivity. In: Quantification in Natural Languages. Dordrecht: Springer, 1995. Pp. 321-362. (In Eng.)

Haspelmath M. Indefinite Pronouns (Oxford Studies in Typology and Linguistic Theory). Oxford: Clarendon Press, 1997. 380 p. (In Eng.)

Haspelmath M., König E. 9 Concessive conditionals in the languages of Europe. In: Auwera J. van der, O Baoill D. P. (eds.) Adverbial Constructions in the Languages of Europe. Berlin, New York: De Gruyter Mouton. 2011. Pp. 563-640. (In Eng.)

Kim M.-J., Jahnke N. The meaning of utterancefinal even. Journal of English Linguistics. 2011. Vol. 39. No. 1. Pp. 36-64. (In Eng.)

König E. Syntax and semantics of additive focus markers from a cross-linguistic perspective. In: Cesare A.-M. de, Andorno C. (eds.) Focus on Additivity: Adverbial Modifiers in Romance, Germanic and Slavic Languages. Amsterdam: John Benjamins, 2017. Pp. 23-44. (In Eng.)

König E. The Meaning of Focus Particles: A Comparative Perspective. London; New York: Routledge, 1991. 218 p. (In Eng.)

Krifka M. Additive particles under stress. Semantics and Linguistic Theory. 1998. Vol. 8. Pp. 111128. (In Eng.)

Logvinova N. N. Non-possessive functions of the third person possessive in Maloe Karachkino dialect of Chuvash. Acta Linguistica
Zaefferer 2019 - Zaefferer D. Conditionals and Unconditionals: Cross-linguistic and Logical Aspects // Semantic universals and universal semantics (D. Zaefferer, ed.). Berlin, Boston: De Gruyter Mouton, 2019. Pp. 210-236.

Petropolitana. 2019. Vol. 15. No. 2. Pp. 86129. (In Russ.)

Ovsyannikova M., Say S., Aplonova E., Smetina A., Sokur E. Oral Corpus of Bashkir: Rakhmetovo and Baimovo Villages. St. Petersburg: Institute for Linguistic Studies (RAS); Moscow: Higher School of Economics (Linguistic Convergence Laboratory). Available at: http://lingconlab.ru/ spoken_bashkir/ (accessed: July 14, 2021). (In Bash.)

Pazelskaya A. G. Discourse marker or syntactic marker: Particle da in Tatar and Chuvash. In: Computational Linguistics and Intellectual Technologies (Dialogue) 2002. Conference proceedings. Available at: http://www. dialog-21.ru/en/digest/2002/articles/ pazelskaya/ (accessed: July 14, 2021). (In Russ.)

Poppe N. Bashkir Manual: Descriptive Grammar and Texts with a Bashkir-English Glossary. The Hague: Mouton \& Co., 1964. 181 p. (In Eng.)

Puchkova A. I. Constructions with coordinative means menän and häm in the Bashkir language. Acta Linguistica Petropolitana. 2017. Vol. 13. No. 1. Pp. 255-283. (In Russ.)

Szabolcsi A. What do quantifier particles do? Linguistics and Philosophy. 2015. Vol. 38. No. 2. Pp. 159-204. (In Eng.)

Tatevosov S. G., Pazelskaya A. G., Suleymanov D. Sh. (eds.) Elements of Tatar in a Typological Perspective: The Mishar Dialect. Moscow: Buki Vedi, 2017. 764 p. (In Russ.)

Tenishev E. R. (ed.) A Comparative Historical Grammar of Turkic Languages: Morphology. Moscow: Nauka, 1988. 560 p. (In Russ.)

Winterstein G., Lai R., Lee D. T. H., Luk Z. P. S. From additivity to mirativity: The Cantonese sentence final particle tim1. Glossa: A Journal of General Linguistics. 2018. Vol. 3. No. 1. Pp. 1-38. (In Eng.)

Yuldashev A. A. (ed.) Grammar of Modern Standard Bashkir. Moscow: Nauka, 1981. 495 p. (In Russ.)

Zaefferer D. Conditionals and unconditionals: Cross-linguistic and logical aspects. In: Zaefferer D. (ed.) Semantic Universals and Universal Semantics. Berlin, Boston: De Gruyter Mouton, 2019. Pp. 210-236. (In Eng.)

Zakiev M. Z. et al. (eds.) Tatar Grammar. In 3 vols. Vol. 2: Morphology. Ibragimov Institute of Language, Literature and History; Kazan Scientific Center (RAS). Kazan: Tatarstan Book Publ., 1993. 397 p. (In Russ.) 